\title{
A DFT Study of Some Structural and Spectral Properties of 4-Methoxyacetophenone Thiosemicarbazone and Its Complexes with Some Transition Metal Chlorides: Potent Antimicrobial Agents
}

\author{
Julius Numbonui Ghogomu and Nyiang Kennet Nkungli \\ Laboratory of Noxious Chemistry and Environmental Engineering, Department of Chemistry, Faculty of Science, \\ University of Dschang, P.O. Box 67, Dschang, Cameroon
}

Correspondence should be addressed to Julius Numbonui Ghogomu; ghogsjuju@hotmail.com

Received 12 June 2016; Revised 4 October 2016; Accepted 13 October 2016

Academic Editor: Kittusamy Senthilkumar

Copyright (c) 2016 J. N. Ghogomu and N. K. Nkungli. This is an open access article distributed under the Creative Commons Attribution License, which permits unrestricted use, distribution, and reproduction in any medium, provided the original work is properly cited.

\begin{abstract}
Recent studies have shown that 4-methoxyacetophenone thiosemicarbazone (MAPTSC) and its complexes with some transition metal chlorides are potent antimicrobial agents. To deepen the understanding of their structure-activity relationships necessary for rational drug design, their structural and spectral properties, along with thione-thiol tautomerism of MAPTSC, have been studied herein using the density functional theory (DFT). From our results, the thione tautomer of MAPTSC is more stable than the thiol counterpart in ethanolic solution, and thione-to-thiol tautomerization is highly precluded at ambient temperature $\left(25^{\circ} \mathrm{C}\right)$ by a high barrier height $\approx 46.41 \mathrm{kcal} / \mathrm{mol}$. MAPTSC can therefore exist as a mixture of the thione (major) and thiol (minor) tautomers in ethanolic solution at room and higher temperatures. Conformational analysis has revealed five possible conformers of the thione tautomer, of which two are stable enough to be isolated at $25^{\circ} \mathrm{C}$. Based on our computed values of MAPTSC-metal(II) binding energies, enthalpies, and Gibbs free energies, the thione tautomer of MAPTSC exhibits a higher affinity for the $\mathrm{d}^{8} \mathrm{metal}$ ions Ni(II), $\mathrm{Pd}(\mathrm{II})$, and $\mathrm{Pt}(\mathrm{II})$ and can therefore efficiently chelate them in chemical and biological systems. Natural population analysis has revealed ligand-metal charge transfer in the MAPTSC complexes studied. A good agreement has been found between calculated and experimentally observed spectral properties (IR, UV-Vis, and NMR).
\end{abstract}

\section{Introduction}

The coordination chemistry of thiosemicarbazones (TSCs) has recently attracted considerable attention because of their variable bonding modes, structural diversity, nonlinear optical properties, and ion-sensing abilities [1,2]. TSCs constitute a distinguished class of biologically active molecules by virtue of their anticancer, antiviral, antibacterial, antifungal, antitumor, antitubercular, and antileprosy activities [3, 4]. They are commonly used as antiparasitic, antimalaria, and antiamoebic agents. Their biological activities are attributed to their ability to form chelates with metal ions in biological systems and the presence of the imine group $(-\mathrm{N}=\mathrm{CH}-)$ in their molecular structures $[5,6]$. It is well established that the transition metal complexes of TSCs are more biologically active than the free ligands, probably due to the increased lipophilicity (which controls the rate of entry into the cell) of the complexes. The presence of metal ions does not only improve upon their biological activities, selectivity, chemical stability, and their usually low water solubility, but also mitigates their side effects [7].

Recently, 4-methoxyacetophenone thiosemicarbazone (MAPTSC) and its transition metal chloride complexes have been synthesized, characterized, and found to exhibit strong to moderate antimicrobial activities $[8,9]$. To the best of our knowledge, the impact of thione-thiol tautomerism on the metal-coordinating ability of MAPTSC has not yet been investigated. The transition metal chloride complexes 
of MAPTSC currently studied were synthesized at $78^{\circ} \mathrm{C}$ in ethanolic solution [9], a temperature high enough to enhance thione-to-thiol tautomerization of MAPTSC since the equilibrium involved is temperature controlled [10]. Apparently, only the complexes of the thione tautomer were reported to be synthesized and characterized, although those of the thiol tautomer might have been formed as well. X-ray diffraction studies which are capable of providing more insight into the nature of these complexes have not been carried out till date. Moreover, an in-depth analysis of the experimentally determined spectral data for these molecules has not yet been performed. To address these issues, quantum chemical calculations are more appropriate and elegant compared to experimental methods. The results obtained from such calculations are commonly used nowadays to investigate the relationship between electronic structure and spectral properties [11]. We have pursued theoretical studies on these molecules in order to provide detailed information on their structures, properties, and relative stability of the thione-thiol tautomers of MAPTSC, all of which is essential for better understanding of their structure-activity relationships as well as their reactivity in chemical and biological systems. In this regard, the current study is aimed at providing a detailed analysis of the structural and spectral properties of MAPTSC along with some of its transition metal chloride complexes, in a bid to facilitate rational drug design using these molecules as precursors.

In this work, we set out mainly to theoretically optimize the geometries of the thione and thiol tautomers of MAPTSC, determine their relative stability and possible conformers, investigate their metal-coordinating abilities, and perform a detailed structural and spectral analyses of the tautomers, along with their $\mathrm{Ni}(\mathrm{II}), \mathrm{Pd}(\mathrm{II}), \mathrm{Pt}(\mathrm{II})$, and $\mathrm{Zn}(\mathrm{II})$ chloride complexes. In a strict sense, we have calculated and analyzed the geometric parameters (bond lengths, bond angles, and dihedral angles), atomic charge distribution, IR vibrational modes, NMR chemical shifts, and electronic absorption spectra of these molecules. Furthermore, MAPTSC-metal(II) binding energies, enthalpies, and Gibbs free energies, as well as thermodynamic parameters associated with thione-thiol tautomerism and rotational isomerism of MAPTSC, have been studied. To determine the suitability of our theoretical approaches, relevant experimental data has been compared with our theoretical results. The density functional theory (DFT) method has been chosen for this study because it is faster and less computationally intensive, takes better account of electron correlation, and has a precise accuracy in reproducing experimental data [12]. In addition, the DFT has been proven to be a very reliable method for transition metal complexes [13] and is generally considered to be a good compromise between accuracy and computational time.

\section{Computational Details}

All quantum chemical calculations were performed with the Gaussian 09W computational package [14]. The preand postprocessing of data were carried out with Gauss
View 5.0.8 [15] and Multiwfn 3.3.6 [16]. The ground state geometries of the molecules studied were optimized without constraints of any sort, using the Becke's three-parameter Lee-Yang-Parr (B3LYP) DFT functional [17]. This functional was chosen because it produces relatively good geometries of transition metal-containing molecular systems [18]. While the geometries of the thione-thiol tautomers and conformers of MAPTSC were fully optimized at the B3LYP/6-31++G(d,p) level of theory, those of the transition metal chloride complexes of the thione tautomer of MAPTSC were optimized at the B3LYP/6-31++G(d,p)/(SDD for metal ions) level of theory. Here, SDD stands for the small core Stuttgart-Dresden effective core potential, which reduces computational cost and includes some relativistic effects in the calculations. To confirm the fully optimized geometries of the molecules as local minima on their potential energy surfaces (PES), harmonic vibrational frequencies were computed at the same level of theory as that used for geometry optimization. No imaginary frequencies were obtained for any of the optimized geometries, ascertaining that they are minima on their respective PES. The restricted closed-shell Kohn-Sham model was adopted for all theoretical calculations reported in this paper, since all molecules studied are closed-shell systems.

The effects of the bulk solvent environment on geometry configurations and absorption spectra were taken into account by means of the polarizable continuum model (PCM), using the integral equation formalism approach (IEFPCM). Time-dependent density functional theory (TD-DFT) calculations at the CAM-B3LYP/6-31G(d,p)/(LANL2DZ for metal ions) level of theory were performed in order to simulate the UV-Vis spectra of the molecules under investigation. Here, the effective core potential LANL2DZ was preferred over SDD for the metal ions because LANL2DZ resulted in significant speed-ups of the TD-DFT calculations but yielded results that agreed remarkably with experimental values. Moreover, negligible discrepancies were observed between the results obtained by employing LANL2DZ for the metal ions and those obtained by using SDD for these metal ions in the complexes currently studied. Isotropic NMR shielding constants were calculated by the gauge independent atomic orbital (GIAO) method.

\section{Results and Discussion}

3.1. Molecular Geometry of MAPTSC. Before computing the molecular properties of metal complexes, it is necessary to analyze the molecular structures of the ligands in order to identify their stable tautomers and conformers. In this regard, we have carried out tautomerism and conformational analyses on MAPTSC.

3.1.1. Hydrogen Atom Migration Studies and Tautomerism Analysis on MAPTSC. Thione-to-thiol tautomerism of MAPTSC in ethanol (elucidated in Figure 1) was simulated via hydrogen atom migration studies. During the process, H23 migrates from the hydrazinic nitrogen (N22) to the thionic sulfur (S25). In Figure 1, A1 and $\mathbf{A} 2$ represent the 

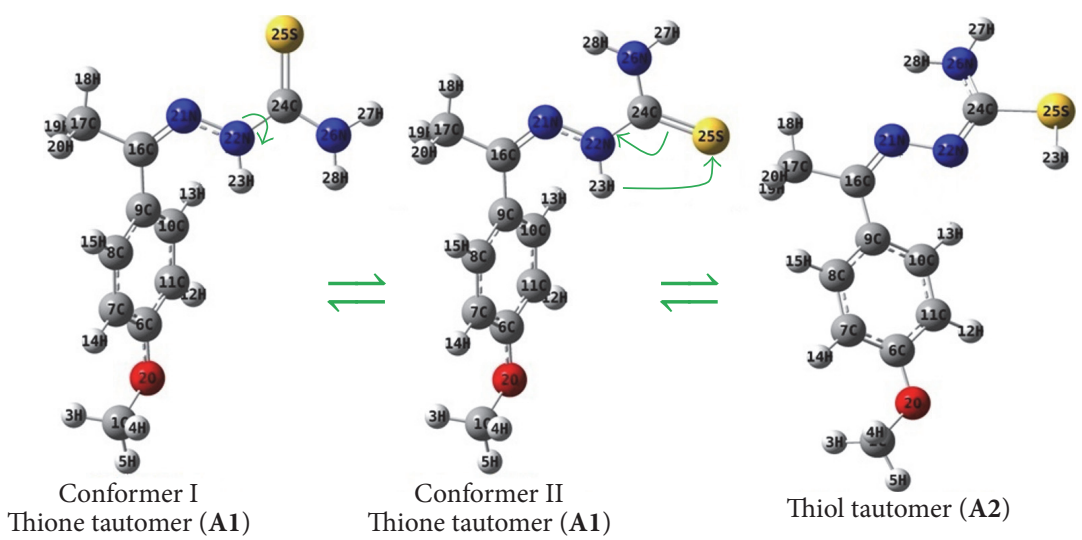

FIGURE 1: The thione-to-thiol tautomerization process for MAPTSC.

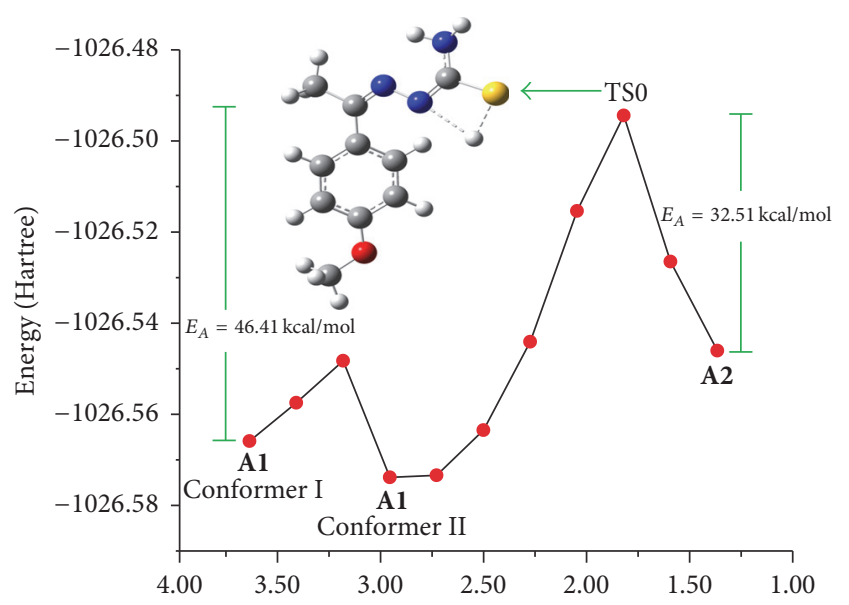

Hydrogen atom migration coordinate (H23-S25 bond distance)

FIGURE 2: PES scan curve for hydrogen atom migration in MAPTSC, simulated at the B3LYP/6-31G $(\mathrm{d}, \mathrm{p})$ level of theory in ethanol as solvent.

thione and thiol tautomers of MAPTSC, respectively. In the course of the PES scan for $\mathrm{H} 23$ atom migration, the H23-S25 bond was chosen as the reaction coordinate. The PES scan was performed by shrinking the bond distance between $\mathrm{H} 23$ and S25 to smaller values at regular intervals of $0.227 \AA$. At each interval, geometry optimization was performed at the B3LYP/6-31G $(\mathrm{d}, \mathrm{p})$ level of theory. The PES scan curve for the hydrogen atom exchange process (Figure 2) has revealed that thione-to-thiol tautomerization of MAPTSC is preceded by free rotation about the N22-C24 bond, which converts conformer I of A1 into conformer II. This rotation occurs concomitantly with reduction in the bond distance between $\mathrm{H} 23$ and S25. This is then followed by intramolecular abstraction of $\mathrm{H} 23$ by S25. A double bond rearrangement from $\mathrm{C} 24=\mathrm{S} 25$ to $\mathrm{N} 22-\mathrm{C} 24$ immediately occurs transforming conformer II of the ligand into A2, via the transition state designated TS0 was in Figure 2. TS0 was confirmed a first-order saddle point on the PES by normal mode analysis at B3LYP/6-31G(d,p) level
TABle 1: The relative energies $\left(\Delta E_{\text {tot }}, \mathrm{kcal} / \mathrm{mol}\right)$, HOMO-LUMO energy gaps $\left(\Delta E_{\mathrm{H}-\mathrm{L}}, \mathrm{kcal} / \mathrm{mol}\right)$, enthalpies of formation $\left(\Delta H_{f}^{o}\right.$, $\mathrm{kcal} / \mathrm{mol})$, and Gibbs free energy of formation $\left(\Delta G_{f}^{o}, \mathrm{kcal} / \mathrm{mol}\right)$ of the thione and thiol tautomers of MAPTSC calculated at B3LYP/6$31 \mathrm{G}(\mathrm{d}, \mathrm{p})$ level of theory at room temperature $(298 \mathrm{~K})$, in ethanol as solvent.

\begin{tabular}{lccccc}
\hline Medium & Tautomer & $\Delta E_{\text {tot }}$ & $\Delta E_{\mathrm{H}-\mathrm{L}}$ & $\Delta H_{f}^{o}$ & $\Delta G_{f}^{o}$ \\
\hline \multirow{2}{*}{ Gas } & Thione & -1.87 & -2.09 & -1.87 & -2.06 \\
\multirow{2}{*}{ Ethanol } & Thiol & 0.00 & 0.00 & 0.00 & 0.00 \\
& Thione & -9.32 & 8.89 & -9.32 & -9.34 \\
& Thiol & 0.00 & 0.00 & 0.00 & 0.00 \\
\multirow{2}{*}{ DMSO } & Thione & -9.74 & 8.50 & -9.74 & -9.94 \\
& Thiol & 0.00 & 0.00 & 0.00 & 0.00 \\
\hline
\end{tabular}

of theory, which yielded one imaginary wavenumber of value $-449.58 \mathrm{~cm}^{-1}$ (unscaled) for $\widetilde{\nu}(\mathrm{S} 25-\mathrm{H} 23)$ stretching vibration. The barrier heights $\left(E_{A}\right)$ for thione-to-thiol and thiol-to-thione tautomerization were found to be $\approx 46.41$ and $32.51 \mathrm{kcal} / \mathrm{mol}$, respectively, signifying that thione-thiol transformations of MAPTSC are nearly hindered in ethanol at room temperature.

In order to determine the most stable tautomer of MAPTSC, the relative stability of $\mathbf{A} \mathbf{1}$ and $\mathbf{A} \mathbf{2}$ was investigated on the basis of their total ground state energies, HOMOLUMO energy gaps, enthalpies, and Gibbs free energies of formation. The relative values of these thermodynamic parameters, calculated in gas and solvent phases, are presented in Table 1 for comparison. It is evident from the hydrogen atom migration curve in Figure 2 that $\mathbf{A} \mathbf{1}$ is lower in energy than A2, implying that the thione tautomer is more stable than the thiol form. The relative energies $\left(\Delta E_{\text {tot }}\right)$ of the tautomers in gas and solvent phases have confirmed the thione tautomer of MAPTSC as being more stable than the thiol counterpart by $1.87,9.32$, and $9.74 \mathrm{kcal} / \mathrm{mol}$ in gas phase, ethanol, and water, respectively. The HOMOLUMO energy gap $\left(\Delta E_{\mathrm{H}-\mathrm{L}}\right)$ is generally used to determine the kinetic stability of a molecular entity. A molecule with a small HOMO-LUMO energy gap is more polarizable and is 
generally associated with a high chemical reactivity and low kinetic stability [12]. The values of $\Delta E_{\mathrm{H}-\mathrm{L}}$ for the tautomers have shown that the thione form is chemically harder than the thiol counterpart in both ethanol and water by 8.89 and $8.50 \mathrm{kcal} / \mathrm{mol}$, respectively, while, in the gas phase, the latter is chemically harder than the former by $2.09 \mathrm{kcal} / \mathrm{mol}$. Hence, the thione tautomer is more kinetically stable than the thiol form in the solvents but less kinetically stable than the thiol tautomer in the gas phase. This is in accordance with the maximum hardness principle, which states that molecules arrange themselves to be as hard as possible.

The Gibbs free energy change for thiol-to-thione tautomerization is $-2.06,-9.34$, and $-9.94 \mathrm{kcal} / \mathrm{mol}$ in gas phase, ethanol, and water, respectively. It is clear from these values that, at room temperature, this conversion is spontaneous and thermodynamically favored in both gas and solvent phases. Moreover, the enthalpy change for this process is $-1.87,-9.32$, and $-9.74 \mathrm{kcal} / \mathrm{mol}$ in gas phase, ethanol, and water, respectively, showing that the process is exothermic in each medium. From the foregoing results, the thione tautomer of MAPTSC is considered more thermodynamically stable than the thiol counterpart. The latter tautomer is less stable because the $\mathrm{H} 23$ atom of the thiol group is orientated such that its intramolecular abstraction by the azomethine nitrogen $\mathrm{N} 22$ is facilitated, thus enhancing thiol-to-thione tautomerization. The orientation of the $\mathrm{H} 23$ atom of the hydrazinic group in conformer I of the thione tautomer is such that its intramolecular abstraction by the thionic sulfur S25 is highly precluded. Hence, thiol-tothione tautomerization of MAPTSC is advantageous over thione-to-thiol conversion, resulting in the thione tautomer being more stable than the thiol form. Based on the results obtained from both hydrogen atom migration and thermodynamic parameters, it can be concluded that the thione tautomer is the most stable form of MAPTSC in both gas and solvent phases, findings which are consistent with the literature [5].

3.1.2. Conformational Search and Analysis on MAPTSC. Molecular geometry and conformational analysis play a very important role in determining structure-activity relationships [19]. From the hydrogen atom migration process (Section 3.1.1), it is clear that free rotation about the covalent bond linking N22 and C24 in the TSC moiety of MAPTSC is a prerequisite for thione-thiol tautomerization. Such a rotation is possible in A1 owing to the flexibility of the N22-C24 single bond but impossible in $\mathbf{A} 2$ due to the rigidity of the N22=C24 double bond. Consequently, a relaxed conformational search has been performed only on the PES of A1, by varying the dihedral angles $\phi_{1}(\mathrm{~N} 21-\mathrm{N} 22-\mathrm{C} 24-\mathrm{S} 25)$ and $\phi_{2}(\mathrm{C} 8-\mathrm{C} 9-\mathrm{C} 16-$ $\mathrm{C} 17$ ) individually from $0^{\circ}$ to $360^{\circ}$ at constant steps of $10^{\circ}$. The geometry at each step was optimized at B3LYP/6-31G(d,p) level of theory. The conformational scan curves generated by torsion about $\phi_{1}(\mathrm{~N} 21-\mathrm{N} 22-\mathrm{C} 24-\mathrm{S} 25)$ and $\phi_{2}(\mathrm{C} 8-\mathrm{C} 9-\mathrm{C} 16-$ $\mathrm{C} 17)$ are plotted on the same axes (Figure 3 ). These scan curves have revealed five possible conformers of $\mathbf{A l}$ denoted $\mathrm{I}-\mathrm{V}$ as shown in Figure 3. The optimized geometries of these conformers are displayed in Figure 4.

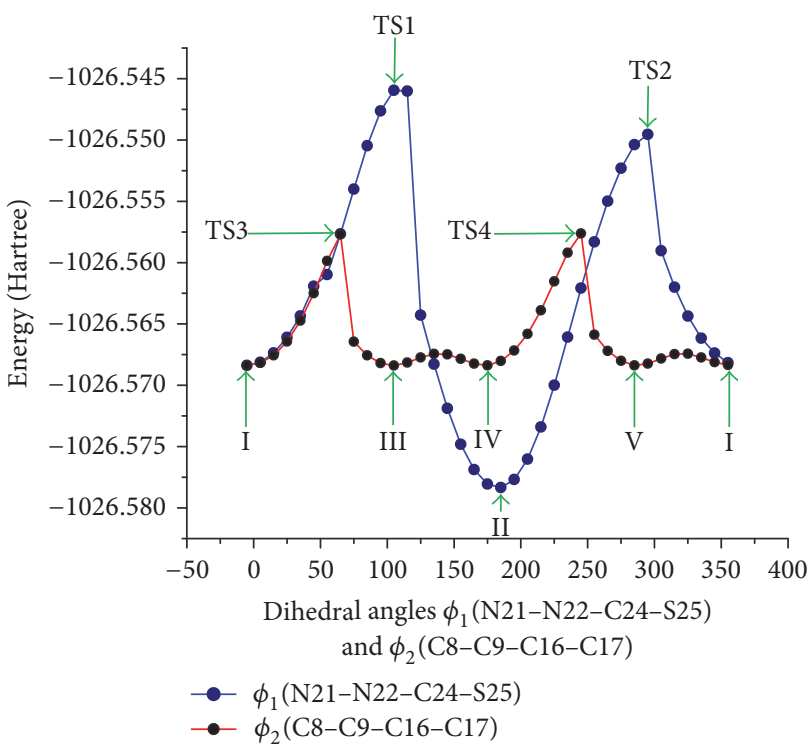

FIGURE 3: PES scan curves obtained by varying the dihedral angles $\phi_{1}(\mathrm{~N} 21-\mathrm{N} 22-\mathrm{C} 24-\mathrm{S} 25)$ (yielding conformers I and II) and $\phi_{2}(\mathrm{C} 8-$ C9-C16-C17) (yielding conformers I, III, IV, and V) from $0^{\circ}$ to $360^{\circ}$.

As depicted in Figure 3, the transformations, conformer I $\rightarrow$ conformer II, conformer II $\rightarrow$ conformer I, conformer I $\rightarrow$ conformer III, and conformer IV $\rightarrow$ conformer $\mathrm{V}$, occur via the transition states designated TS1, TS2, TS3, and TS4, respectively (their geometries are shown in Figure S1 of Supporting Information available online at http://dx.doi.org/10.1155/2016/9683630). These transition states were confirmed first-order saddle points on the PES by normal mode analysis studies at B3LYP/6-31G(d,p) level of theory, and in each case one imaginary wavenumber of value $-95.27,-94.04,-46.76$, and $-53.21 \mathrm{~cm}^{-1}$ (unscaled) was obtained for TS1, TS2, TS3, and TS4, respectively. The aforementioned transformations also proceed across the rotational barrier heights: $14.08,18.07,6.70$, and $6.75 \mathrm{kcal} / \mathrm{mol}$, respectively (a detailed analysis of these barrier heights is presented in Table S2 of Supporting Information). These barrier heights are accessible at room temperature $\left(25^{\circ} \mathrm{C}\right)$, signifying that the five conformers of Al can exist at this temperature. Although all of the conformers are possible at $25^{\circ} \mathrm{C}$, not all of them can be isolated in appreciable amounts at this temperature. The barrier heights for conformer I $\rightarrow$ conformer II and conformer II $\rightarrow$ conformer I conversions are high enough to permit their isolation at $25^{\circ} \mathrm{C}$ in appreciable quantities. However, the low barrier height for the conversion of conformer I to conformer III reduces the amount of conformer I that could be isolated at $25^{\circ} \mathrm{C}$. It is obvious from Figure 3 that rapid conversion of conformer III to conformer IV occurs at ambient temperature. The barrier height for the transformation of conformer IV to conformer V is too low, rendering the isolation of the former almost impossible at room temperature. It is also clear from Figure 3 that conformer $\mathrm{V}$ is rapidly converted into conformer I. Therefore, 

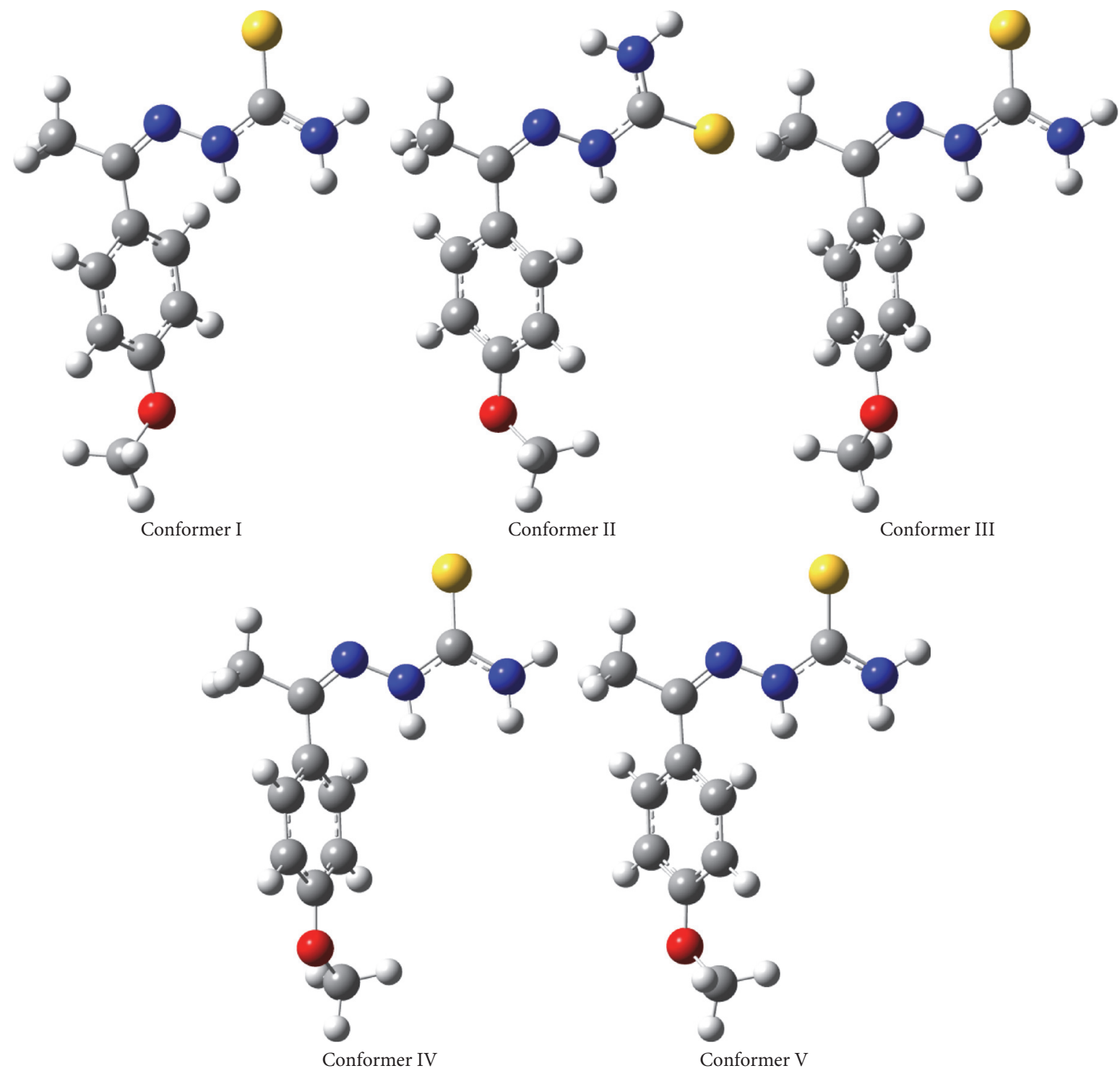

FIGURE 4: Optimized geometries of the conformers of A1 obtained by varying the dihedral angles $\phi_{1}(\mathrm{~N} 21-\mathrm{N} 22-\mathrm{C} 24-\mathrm{S} 25)$ (yielding conformers I and II) and $\phi_{2}(\mathrm{C} 8-\mathrm{C} 9-\mathrm{C} 16-\mathrm{C} 17)$ (yielding conformers I, III, IV, and V) from $0^{\circ}$ to $360^{\circ}$.

of the five conformers of Al, only conformers I and II can be isolated in relatively high yields at room temperature.

The computed relative energies of the conformers I and II, I and III, I and IV, and I and V are $-6.2489,-0.0036,0.0017$, and $-0.0010 \mathrm{kcal} / \mathrm{mol}$, respectively (a detailed analysis of these relative energies is presented in Table S2 of Supporting Information). It is worth noting here that the relative energy of any pair of conformers $x$ and $y$ has been calculated as energy of $y$ - energy of $x$. In a case where $y$ is lower in energy than $x$, the relative energy is negative and if otherwise, the relative energy is positive. On this basis, it is clear that conformer II is much lower in energy than conformer I. Compared to conformer I, conformers III and $\mathrm{V}$ are slightly lower in energy, whereas conformer IV is slightly higher in energy. It is therefore obvious from these relative energies that, among the five possible conformers of Al at room temperature, conformer II is the most stable and the rest of the conformers are of approximately at the same stability.

3.2. Molecular Geometries of the Complexes Studied. The more stable thione tautomer of MAPTSC was preferred over the less stable thiol form in the molecular structures of the complexes. The ground state geometries of the complexes $\left[\mathrm{Ni}(\mathrm{Al}) \mathrm{Cl}_{2}\right](\mathbf{B}),\left[\mathrm{Pd}(\mathrm{Al}) \mathrm{Cl}_{2}\right](\mathbf{C}),\left[\mathrm{Pt}(\mathrm{Al}) \mathrm{Cl}_{2}\right]$ $(\mathrm{D})$, and $\left[\mathrm{Zn}(\mathrm{Al}) \mathrm{Cl}_{2}\right](\mathrm{E})$ were optimized at the B3LYP/6$31++\mathrm{G}(\mathrm{d}, \mathrm{p}) /(\mathrm{SDD}$ for metal ions) in gas and solvent phases without constraints on symmetry, bond lengths, bond angles, or dihedral angles. The gas phase optimized geometries of $\mathbf{B}-$ E are presented in Figure 5. 


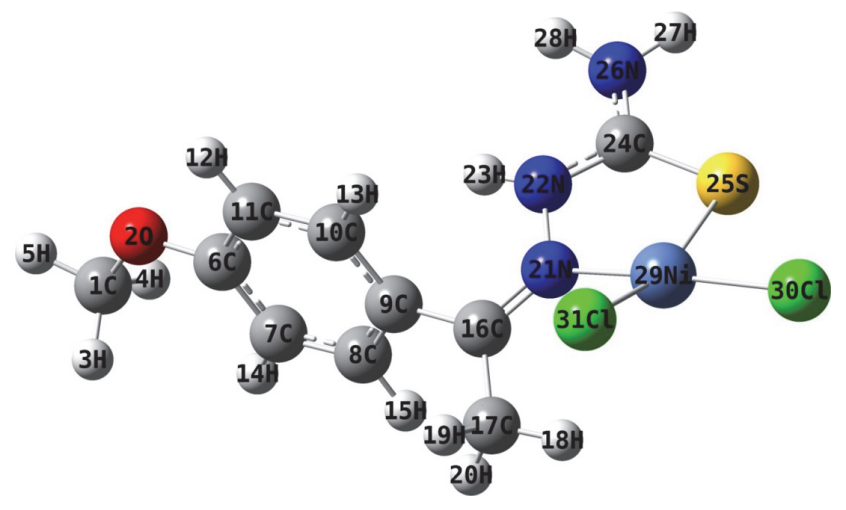

(B)

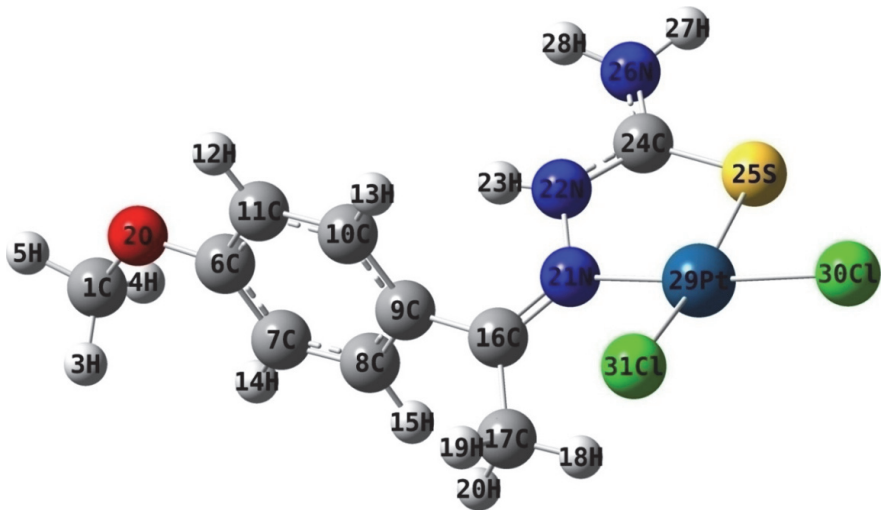

(D)

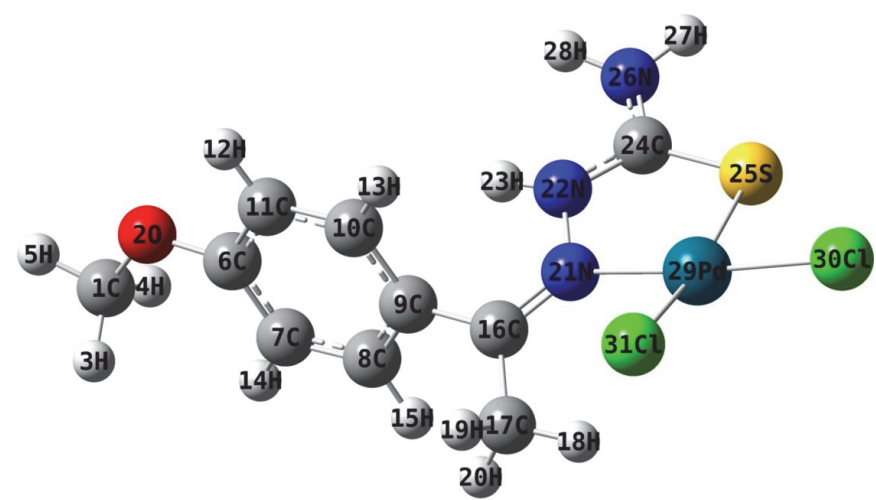

(C)

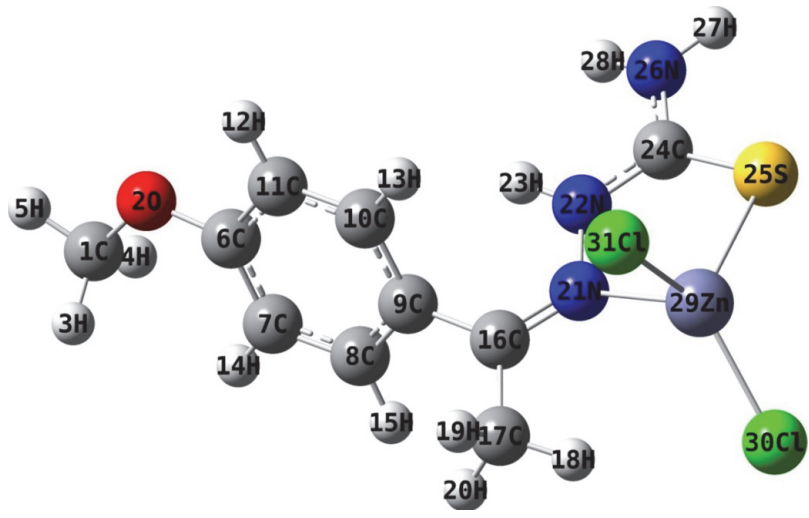

(E)

Figure 5: Optimized geometries of $\left[\mathrm{Ni}(\mathrm{Al}) \mathrm{Cl}_{2}\right](\mathbf{B}) ;\left[\mathrm{Pd}(\mathrm{Al}) \mathrm{Cl}_{2}\right](\mathbf{C}) ;\left[\mathrm{Pt}(\mathrm{A1}) \mathrm{Cl}_{2}\right](\mathbf{D})$; and $\left[\mathrm{Zn}(\mathrm{Al}) \mathrm{Cl}_{2}\right](\mathbf{E})$ at B3LYP/6-31++G(d,p)/(SDD for metal ions) level of theory in gas phase.

Selected gas phase geometric parameters (bond lengths, bond angles, and dihedral angles) in the TSC moieties of all molecules studied and around the central metal ions in the complexes are listed in Table S3 (Supporting Information). In general, the neutral form of any TSC (thione tautomer) contains a formal C-S double bond of length 1.67-1.72 $\AA$, while the deprotonated thiol form possesses a formal C$S$ single bond of length 1.71-1.80 $\AA$ [20]. In the case of MAPTSC, the calculated C-S bond lengths in the thione form $(1.665 \AA)$ and thiol form $(1.785 \AA)$ are in good agreement with literature values. The $\mathrm{C}-\mathrm{N}$ and $\mathrm{N}-\mathrm{N}$ bond lengths in the TSC moieties of all molecules studied are very similar $(\approx 1.4 \AA)$ and lie between the optimal C-N/N-N bond length $(1.5 \AA)$ and the optimal $\mathrm{C}=\mathrm{N} / \mathrm{N}=\mathrm{N}$ bond lengths $(1.3$ and $1.2 \AA$, resp.). This is a clear indication of extensive electron delocalization within the TSC moiety, which helps to improve upon the second harmonic generation (SHG) efficiency of MAPTSC and its metal complexes. The bond lengths $\mathrm{R}_{1}(\mathrm{C} 24-\mathrm{S} 25)$, $\mathrm{R}_{4}(\mathrm{~N} 22-\mathrm{N} 21)$, and $\mathrm{R}_{5}(\mathrm{C} 16-\mathrm{N} 21)$ are longer in the complexes than in the free ligand A1. This can be attributed to the coordination of S25 and N21 to the central metal ions. The metal-ligand bond lengths in the complexes are similar and are averagely $2.25 \AA$.

It is clear from Table $\mathrm{S} 3$ that tautomerism alters the bond lengths and angles within the TSC moieties of the thione and thiol tautomers of MAPTSC. These structural changes can lead to the tautomers exhibiting different antimicrobial and anticancer potencies. The average value of the bond angles $\theta_{1}-\theta_{5}$ in the TSC moieties of all molecules investigated is $119.31^{\circ}$, implying that the carbon and nitrogen atoms in these moieties are approximately $\mathrm{sp}^{2}$ hybridized. This ascertains the occurrence of $\pi$-conjugation within these moieties, accounting for their extensive electron delocalization. The average value of the bond angles $\theta_{6}(\mathrm{~S} 25-\mathrm{M} 29-\mathrm{N} 21), \theta_{7}(\mathrm{~N} 21-$ $\mathrm{M} 29-\mathrm{Cl} 31), \theta_{8}(\mathrm{Cl} 30-\mathrm{M} 29-\mathrm{S} 25)$, and $\theta_{9}(\mathrm{Cl} 31-\mathrm{M} 29-\mathrm{Cl} 30)$ in complexes $\mathbf{B}, \mathbf{C}$, and $\mathbf{D}$ is $90.18^{\circ}$, which indicates that these complexes adopt a nearly square planar geometry around their respective central metal ions. The values of $\theta_{6}-\theta_{9}$ in complex $\mathbf{E}$ suggest a highly distorted tetrahedral geometry around the central $\mathrm{Zn}(\mathrm{II})$ ion. The planarity of the TSC moiety can be judged from the values of the dihedral angles $\phi_{1}(\mathrm{~N} 21-\mathrm{N} 22-\mathrm{C} 24-\mathrm{S} 25)$ and $\phi_{3}(\mathrm{~N} 21-\mathrm{N} 22-\mathrm{C} 24-\mathrm{N} 26)$ which should normally be $0^{\circ}$ and $180^{\circ}$, respectively, in a perfectly planar TSC moiety. From the values of these torsional angles in Table S3, it can be concluded that the TSC moieties of all molecules investigated are somewhat planar, enhancing $\pi$ conjugation and electron delocalization.

3.3. Binding Energies and Thermodynamic Parameters for Metal-MAPTSC Interactions. The complexes investigated in 
TABLE 2: Binding energies $\left(\Delta E_{\text {int }}, \mathrm{kcal} / \mathrm{mol}\right)$, enthalpies $\left(\Delta H_{\text {int }}\right.$, $\mathrm{kcal} / \mathrm{mol})$, and Gibbs free energies $\left(\Delta G_{\text {int }}, \mathrm{kcal} / \mathrm{mol}\right)$ of complex formation between $\mathbf{A} \mathbf{1}$ and some transition metal chlorides at room temperature.

\begin{tabular}{lcccc}
\hline \multirow{2}{*}{ Property } & \multicolumn{4}{c}{ Transition metal ion $[\mathrm{M}(\mathrm{II})]$ present in complex } \\
& $\mathrm{Ni}^{2+}$ & $\mathrm{Pd}^{2+}$ & $\mathrm{Pt}^{2+}$ & $\mathrm{Zn}^{2+}$ \\
\hline$\Delta E_{\text {int }}$ & -35.23 & -37.99 & -42.81 & -3.18 \\
$\Delta H_{\text {int }}$ & -35.83 & -38.59 & -43.40 & -3.77 \\
$\Delta G_{\text {int }}$ & -21.00 & -24.07 & -27.65 & 7.22 \\
\hline
\end{tabular}

this study were originally synthesized by refluxing an ethanolic solution of MAPTSC with ethanolic solutions of the corresponding metal salts $\left(\mathrm{NiCl}_{2} \cdot 6 \mathrm{H}_{2} \mathrm{O}, \mathrm{PdCl}_{2} \cdot 6 \mathrm{H}_{2} \mathrm{O}\right.$, $\mathrm{PtCl}_{2} \cdot 6 \mathrm{H}_{2} \mathrm{O}$, and $\left.\mathrm{ZnCl}_{2} \cdot 6 \mathrm{H}_{2} \mathrm{O}\right)$ [9]. In the reaction solution, each transition metal ion $\left(\mathrm{M}^{2+}\right)$ would first bind to two $\mathrm{Cl}^{-}$ ions due to the strong cation-anion electrostatic force of attraction, leading to the formation of the neutral fragment $\mathrm{MCl}_{2}$. Then, MAPTSC coordinates to the transition metal ion present in the $\mathrm{MCl}_{2}$ fragment yielding the complexes studied. To determine the coordinating ability or affinity of the thione tautomer of MAPTSC towards the transition metal ions studied in ethanol, the $\mathrm{Al}-\mathrm{MCl}_{2}$ binding energies $\left(\Delta E_{\text {int }}\right)$, enthalpies $\left(\Delta H_{\text {int }}\right)$, and Gibbs free energies $\left(\Delta G_{\text {int }}\right)$ at room temperature were calculated for $\mathrm{M}=\mathrm{Ni}^{2+}, \mathrm{Pd}^{2+}, \mathrm{Pt}^{2+}$, and $\mathrm{Zn}^{2+}$. The values of $\Delta E_{\text {int }}, \Delta H_{\text {int }}$, and $\Delta G_{\text {int }}$ (tabulated in Table 2) were calculated using

$$
\begin{aligned}
& \Delta E_{\mathrm{int}}=E_{\left[\mathrm{M}(\mathrm{A} 1) \mathrm{Cl}_{2}\right]}-\left(E_{\mathrm{A} 1}+E_{\mathrm{MCl}_{2}}\right) \\
& \Delta H_{\mathrm{int}}=H_{\left[\mathrm{M}(\mathrm{A} 1) \mathrm{Cl}_{2}\right]}^{o}-\left(H_{\mathrm{A} 1}^{o}+H_{\mathrm{MCl}_{2}}^{o}\right) \\
& \Delta G_{\mathrm{int}}=G_{\left[\mathrm{M}(\mathrm{A} 1) \mathrm{Cl}_{2}\right]}^{o}-\left(G_{\mathrm{A} 1}^{o}+G_{\mathrm{MCl}_{2}}^{o}\right) .
\end{aligned}
$$

Here, $E, H^{o}$, and $G^{o}$, respectively, represent the thermal energies, enthalpies, and Gibbs free energies of the respective species at $298.15 \mathrm{~K}$ and $1.00 \mathrm{~atm}$. The values of these parameters were obtained from thermochemical analysis at B3LYP/6-31++G(d,p)/(SDD for metal ions) level of theory.

From the computed values of $\Delta E_{\text {int }}, \Delta H_{\text {int }}$, and $\Delta G_{\text {int }}$, it is evident that $\mathbf{A} \mathbf{1}$ is highly selective towards the metal ions studied, and the selectivity decreases in the following order: $\mathrm{Pt}^{2+}>\mathrm{Pd}^{2+}>\mathrm{Ni}^{2+}>\mathrm{Zn}^{2+}$. It is also clear from the values in Table 2 that the formation of $\left[\mathrm{Zn}(\mathrm{Al}) \mathrm{Cl}_{2}\right]$ in ethanolic solution is not thermodynamically feasible at room temperature, since $\Delta G_{\text {int }}$ for $\mathrm{Al}-\mathrm{ZnCl}_{2}$ binding is positive. Although $\Delta E_{\text {int }}$ and $\Delta H_{\text {int }}$ for this process are negative, their numerical values are very small, somewhat confirming the nonfeasibility of $\mathrm{Al}-\mathrm{ZnCl}_{2}$ binding in ethanolic solution at $25^{\circ} \mathrm{C}$. From the trend shown by the values of $\Delta E_{\text {int }}, \Delta H_{\text {int }}$, and $\Delta G_{\text {int }}$, it is clear that the complexation reactions leading to the formation of the $\mathrm{Ni}(\mathrm{II}), \mathrm{Pd}(\mathrm{II})$, and $\mathrm{Pt}(\mathrm{II})$ chlorides complexes of ligand $\mathbf{A} \mathbf{1}$ are thermodynamically feasible in ethanolic solution at room temperature. Based on these results, it can be concluded that the thione tautomer of MAPTSC has a higher affinity for the $\mathrm{d}^{8}$ metal ions $\mathrm{Ni}(\mathrm{II})$,
$\mathrm{Pd}(\mathrm{II})$, and $\mathrm{Pt}(\mathrm{II})$ and can efficiently chelate them in chemical and biological systems.

3.4. Atomic Charge Analysis. Atomic charges are important parameters in structure-property and structure-activity relationships, affecting dipole moments, molecular polarizabilities, acid-base properties, and many other molecular properties [20]. In metal complexes, the interactions between the ligands and the metal ions manifest themselves in the charges on the ligand moieties and the metal ions [21-23]. Among the existing atomic charge models, we chose natural population analysis (NPA) [24] and Mulliken's population analysis (MPA) [25] for atomic charge calculations on A1 and its metal chloride complexes B-E. The MPA method was chosen because it has been the most widely used population analysis method for determining atomic charges, although its results tend to vary with basis set size and yields unnatural values in some cases $[13,21,26]$. The NPA atomic charge model was chosen based on the established fact that it is not basis set dependent and is seemingly the most preferred population analysis method nowadays $[26,27]$. The MPA and NPA atomic charges on selected atoms in $\mathbf{A 1}$ and its complexes studied are listed in Table S4 (Supporting Information), for comparison. Significant discrepancies are observed between the NPA and MPA charges, albeit a few exceptions. Since MPA yields unnatural charges in some cases, the rest of the discussion pertaining to atomic charge analysis is based only on the NPA charges.

The transition metal ions in the complexes studied are formally in the second oxidation state, but the computed natural charges for these ions $\left(\mathrm{Ni}^{+0.3321}, \mathrm{Pd}^{+0.2025}, \mathrm{Pt}^{+0.1030}\right.$, and $\mathrm{Zn}^{+0.9438}$ ) are considerably lower than +2 , signifying that they preserve most of the electrons withdrawn from the ligands. Therefore, ligand-to-metal electron donations are advantageous over metal-to-ligand back donations in these complexes. This charge transfer pattern is corroborated by the changes undergone by the atomic charges on the ligand donor atoms, upon coordination to the central metal ions. The magnitude of the negative charge on the N21 donor atom of uncomplexed $\mathbf{A} \mathbf{1}$ (natural charge is -0.2774) reduces slightly in the complexes $\mathbf{B}, \mathbf{C}$, and $\mathbf{D}$ (natural charges range from -0.2527 to -0.2680 ) but witnesses a modest increment in complex $\mathbf{E}$ (natural charge is -0.3440). This shows that A1to-metal donation of electrons occurs in $\mathbf{B}, \mathbf{C}$, and $\mathbf{D}$ via atom N21, whereas metal-to-A1 back donation of electrons occurs in $\mathbf{E}$ through N21. In the case of the S25 donor atom of ligand A1, the magnitude of its negative charge in uncomplexed A1 (natural charge is -0.3681 ) suffers a drastic reduction in the complexes $\mathbf{B}, \mathbf{C}$, and $\mathbf{D}$ (natural charges range from +0.0157 to +0.1030 ) and a modest reduction in complex $\mathbf{E}$ (natural charge is -0.1977). Hence, A1-to-metal charge transfer occurs in all complexes studied via atom S25. This charge transfer is moderate in complex $\mathbf{E}$ and substantial in the complexes $\mathbf{B}, \mathbf{C}$, and $\mathbf{D}$. The natural charges on the $\mathrm{Cl} 30$ and $\mathrm{Cl} 31$ ligands are drastically reduced from the formal -1 charge on a free chloride ion to an average charge -0.5535 following their coordination to the central metal ions. This is indicative of significant electron donation from $\mathrm{Cl} 30$ and $\mathrm{Cl} 31$ to the 
TABLE 3: Calculated harmonic vibrational frequencies for ligand $\mathbf{A} 1$ and the complexes B-E at B3LYP/6-31++G(d,p)/(SDD for metal ions) level and the corresponding FT-IR frequencies for B-D.

\begin{tabular}{|c|c|c|c|c|c|c|c|c|c|}
\hline \multicolumn{2}{|c|}{ A1 } & \multicolumn{2}{|c|}{ B } & \multicolumn{2}{|c|}{$\mathrm{C}$} & \multicolumn{2}{|c|}{ D } & \multirow{2}{*}{$\begin{array}{c}\mathbf{E} \\
\tilde{v}_{\mathrm{cal}}\end{array}$} & \multirow{2}{*}{ Assignment } \\
\hline$\tilde{\nu}_{\mathrm{cal}}^{\mathrm{a}}$ & $\tilde{v}_{\exp }^{b}$ & $\widetilde{v}_{\mathrm{cal}}$ & $\tilde{v}_{\exp }$ & $\tilde{v}_{\mathrm{cal}}$ & $\tilde{v}_{\exp }$ & $\tilde{v}_{\mathrm{cal}}$ & $\widetilde{v}_{\exp }$ & & \\
\hline 3415 & $3373(3400)$ & 3449 & 3346 & 3453 & 3347 & 3451 & 3350 & 3452 & $\tilde{\nu}_{s}\left(\mathrm{NH}_{2}\right)^{\mathrm{c}}$ \\
\hline 3356 & $3262(3247)$ & 3378 & 3252 & 3375 & 3245 & 3380 & 3254 & 3381 & $\widetilde{\nu}(\mathrm{N}-\mathrm{H})$ \\
\hline 1621 & $1618(1588)$ & 1602 & 1606 & 1595 & 1606 & 1575 & 1605 & 1617 & $\widetilde{\nu}(\mathrm{C}=\mathrm{N})$ \\
\hline 1367 & 1178 & 1369 & 1174 & 1374 & 1178 & 1375 & 1160 & 1377 & $\widetilde{v}(\mathrm{C}=\mathrm{S})$ \\
\hline- & - & 487 & - & 488 & - & 491 & - & 482 & $\widetilde{v}(\mathrm{M}-\mathrm{N})$ \\
\hline- & - & 438 & - & 440 & - & 446 & - & 434 & $\widetilde{\nu}(\mathrm{M}-\mathrm{S})$ \\
\hline- & - & 351 & - & 333 & - & 328 & - & 295 & $\tilde{\nu}(\mathrm{M}-\mathrm{Cl})$ \\
\hline
\end{tabular}

${ }^{\mathrm{a}} \widetilde{v}_{\text {cal }}$ represents wavenumbers calculated in this work.

${ }^{\mathrm{b}} \widetilde{v}_{\text {exp }}$ represents experimental wavenumbers from [9] and those in parentheses from [8].

${ }^{c} \widetilde{v}_{s}$ represents symmetric stretching vibrations of $\mathrm{N}-\mathrm{H}$ bonds in $\mathrm{NH}_{2}$.

central metal ions. From the foregoing results, it is clear that appreciable metal-to-ligand back donation of electrons only occurs in complex E. This fact is further buttressed by the relatively large positive charge on its central $\mathrm{Zn}$ ion $(+0.9438)$.

\subsection{Infrared (IR) Vibrational Analysis. Molecular vibrations} have attracted much attention from experimental and theoretical chemists as they are extensively used in chemical analysis and in chemical kinetics studies [28]. To determine the mode of coordination of ligand A1 to the transition metal ions investigated in this research from a purely IR vibrational point of view, the IR spectra of all molecules studied have been calculated at B3LYP/6-31++G(d,p)/(SDD for metal ions) level of theory in gas phase. Pertinent theoretical IR vibrational frequencies for the molecules investigated are listed in Table 3, along with their probable assignments. The assignments of these vibrational modes have been aided by the animation option of Gauss View 5.0.8. Also listed in Table 3 are the corresponding FT-IR frequencies of the molecules, for comparison with the theoretical values. The calculated frequencies are found to be slightly overestimated compared to the experimentally observed values. This is attributable to the neglect of anharmonic effects and the use of isolated molecules in the calculations [22, 29]. In order to improve the agreement between calculated and experimentally observed IR wavenumbers, the calculated values have been scaled down with the scale factor 0.9614 $[26,30]$. To better compare theoretical and experimental IR frequencies, a correlation equation (2) has been established based on the vibrational modes of complexes B-D. The large correlation coefficient $\left(R^{2}=0.993\right)$ shows a good linear agreement between the calculated (scaled) and FTIR frequencies. This ascertains the suitability of the level of theory employed in these calculations:

$$
\widetilde{v}_{\text {cal }}=0.995 \tilde{v}_{\exp }-92.83 \quad\left(R^{2}=0.993\right),
$$

where $\widetilde{\nu}_{\text {cal }}$ and $\widetilde{v}_{\text {exp }}$ represent calculated and experimental wavenumbers, respectively.

To determine the coordination mode of ligand A1 based on vibrational analysis, its IR vibrational spectrum has been compared with those of its metal chloride complexes. The spectra have shown the persistence of two small bands in the range $3453-3356 \mathrm{~cm}^{-1}$ corresponding to stretching vibrations of the N22-H23 bond and symmetric stretching vibrations of $\mathrm{N} 26-\mathrm{H} 27$ and N26-H28 bonds of the amino group $\left(\mathrm{NH}_{2}\right)$. This is indicative of the noncoordination of the nitrogen atoms $\mathrm{N} 22$ and N26 to the central metal ions. In the spectrum of $\mathbf{A l}$, the band at $1621 \mathrm{~cm}^{-1}$ is assigned to the stretching vibration of the azomethine group $(\mathrm{C}=\mathrm{N})$. In the complexes, this band is shifted towards smaller wavenumbers by $46-4 \mathrm{~cm}^{-1}$, suggesting the coordination of the azomethine nitrogen N21 to the central metal ions. The band at $1367 \mathrm{~cm}^{-1}$ in the spectrum of $\mathbf{A 1}$ and similar bands in the range 1377$1369 \mathrm{~cm}^{-1}$ in the spectra of the complexes are assigned to the stretching vibration of the $\mathrm{C}=\mathrm{S}$ group. In the complexes, these bands are shifted towards larger wavenumbers by $10-2 \mathrm{~cm}^{-1}$, suggesting the coordination of the thionic sulfur S25 to the central metal ions. From these results, it can be concluded that $\mathbf{A l}$ acts as a bidentate chelating ligand and coordinates to the metal ions via the azomethine nitrogen N21 and the thionic sulfur S25. These findings are further supported by the appearance of new bands in the regions $491-482 \mathrm{~cm}^{-1}$ and $446-434 \mathrm{~cm}^{-1}$ due to $\widetilde{v}(\mathrm{M}-\mathrm{N})$ and $\widetilde{\nu}(\mathrm{M}-\mathrm{S})$ stretching vibrations, respectively, in the complexes.

3.6. Nuclear Magnetic Resonance (NMR) Spectral Analysis. $\mathrm{NMR}$ is useful in determining the structure of an organic compound by revealing the carbon skeleton and the attached hydrogen atoms [31]. Experimentally observed ${ }^{13} \mathrm{C} N \mathrm{NM}$ chemical shifts were not found in the literature for the complexes currently studied. To better describe the carbon skeletons of all investigated molecules, their isotropic NMR shielding constants were calculated by the gauge independent atomic orbital (GIAO) method in DMSO as solvent. The calculations were performed using the B3LYP functional in conjunction with the pseudopotential LANL2DZ for the transition metal ions and the Pople style basis set 6$31+G(d, p)$ for the rest of the elements. The theoretical ${ }^{1} \mathrm{H}$ and ${ }^{13} \mathrm{C}$ NMR chemical shifts of the molecules are listed in Table 4 along with the available experimental values, for 
TABLE 4: Experimentally observed and calculated ${ }^{1} \mathrm{H}$ and ${ }^{13} \mathrm{C}$ isotropic chemical shifts (with respect to TMS, all values in ppm) for A1 and its complexes B-E. The values were calculated at B3LYP/6-31+G(d,p)/(LANL2DZ for metal ions) level of theory in DMSO as solvent, by the GIAO method.

\begin{tabular}{|c|c|c|c|c|c|c|c|c|c|}
\hline \multirow{2}{*}{ Atom $^{\mathrm{a}}$} & \multicolumn{2}{|c|}{ A1 } & \multicolumn{2}{|c|}{ B } & \multicolumn{2}{|c|}{$\mathrm{C}$} & \multicolumn{2}{|c|}{ D } & \multirow{2}{*}{$\begin{array}{c}\mathbf{E} \\
\delta_{\mathrm{cal}}^{\mathrm{b}}\end{array}$} \\
\hline & $\delta_{\mathrm{cal}}^{\mathrm{b}}$ & $\delta_{\exp }{ }^{c}$ & $\delta_{\mathrm{cal}}^{\mathrm{b}}$ & $\delta_{\exp }{ }^{\mathrm{d}}$ & $\delta_{\mathrm{cal}}^{\mathrm{b}}$ & $\delta_{\exp }{ }^{\mathrm{d}}$ & $\delta_{\mathrm{cal}}^{\mathrm{b}}$ & $\delta_{\exp }{ }^{\mathrm{d}}$ & \\
\hline H3 & 3.83 & 3.78 & 3.90 & 3.80 & 3.93 & 3.81 & 3.90 & 3.83 & 3.90 \\
\hline $\mathrm{H} 4$ & 3.84 & 3.78 & 3.88 & 3.80 & 3.90 & 3.81 & 3.88 & 3.83 & 3.89 \\
\hline H5 & 4.19 & 3.78 & 4.21 & 3.86 & 4.22 & 3.86 & 4.25 & 3.93 & 4.23 \\
\hline H12 & 7.23 & 7.39 & 7.21 & 6.90 & 7.28 & 6.90 & 7.22 & 6.80 & 7.23 \\
\hline H13 & 7.49 & 7.52 & 7.26 & 6.90 & 7.45 & 6.90 & 7.46 & 6.90 & 7.44 \\
\hline H14 & 7.18 & 7.39 & 7.24 & 6.90 & 7.30 & 6.90 & 7.23 & 6.80 & 7.27 \\
\hline H15 & 7.63 & 7.52 & 7.57 & 6.90 & 7.62 & 6.90 & 7.68 & 6.90 & 7.64 \\
\hline $\mathrm{H} 23$ & 8.80 & 10.10 & 8.73 & 7.60 & 8.90 & 10.00 & 8.79 & 10.85 & 8.75 \\
\hline $\mathrm{H} 27$ & 5.68 & 7.52 & 6.02 & 7.60 & 5.84 & 7.80 & 5.85 & 7.90 & 5.90 \\
\hline $\mathrm{H} 28$ & 5.16 & 7.52 & 5.54 & 7.60 & 5.46 & 7.80 & 5.38 & 7.90 & 5.26 \\
\hline $\mathrm{C} 1$ & 55.81 & 54.59 & 55.19 & - & 55.26 & - & 54.96 & - & 55.41 \\
\hline C6 & 158.57 & 159.61 & 160.05 & - & 159.89 & - & 160.07 & - & 160.29 \\
\hline C7 & 108.53 & 112.94 & 108.84 & - & 109.18 & - & 109.47 & - & 108.85 \\
\hline C8 & 128.51 & 129.45 & 128.53 & - & 128.69 & - & 128.64 & - & 128.72 \\
\hline C9 & 123.44 & 112.94 & 121.86 & - & 120.88 & - & 120.83 & - & 121.01 \\
\hline $\mathrm{C} 10$ & 124.80 & 112.94 & 124.77 & - & 124.53 & - & 125.00 & - & 124.34 \\
\hline C11 & 115.93 & 112.94 & 116.16 & - & 116.27 & - & 116.01 & - & 116.74 \\
\hline $\mathrm{C} 16$ & 155.71 & 147.21 & 181.29 & - & 177.04 & - & 175.53 & - & 167.16 \\
\hline $\mathrm{C} 17$ & 27.75 & 13.24 & 33.26 & - & 34.07 & - & 35.00 & - & 27.51 \\
\hline $\mathrm{C} 24$ & 177.20 & 178.02 & 176.45 & - & 176.50 & - & 176.37 & - & 173.26 \\
\hline
\end{tabular}

${ }^{\mathrm{a}}$ For atomic numbering, refer to Figures 1 and 4.

${ }^{\mathrm{b}} \delta_{\text {cal }}$ theoretical chemical shifts calculated in this work.

${ }^{\mathrm{c}} \delta_{\text {exp }}$ experimentally observed chemical shifts from [8].

${ }^{\mathrm{d}} \delta_{\text {exp }}$ experimentally observed chemical shifts from [9].

comparison. The calculated chemical shifts $\left(\delta_{\text {cal }}\right)$ reported in this table were computed relative to those of tetramethylsilane (TMS) using (3) $[28,32]$. In this equation, $\delta_{\mathrm{abc}}^{x}$ and $\delta_{\mathrm{abc}}^{\mathrm{TMS}}$ represent computed absolute isotropic shielding constants of the carbon and hydrogen atoms in the molecules studied and TMS, respectively. Furthermore, $x$ represents any carbon or hydrogen atom in the molecules under investigation. The values of $\delta_{\mathrm{abc}}^{x}$ and $\delta_{\mathrm{abc}}^{\mathrm{TMS}}$ were calculated at the same level of theory [B3LYP/6-31+G(d,p)/(LANL2DZ for metal ions)]:

$$
\delta_{\mathrm{cal}}^{x}=\delta_{\mathrm{abc}}^{\mathrm{TMS}}-\delta_{\mathrm{abc}}^{x} .
$$

A good agreement has been found between the calculated and experimentally observed chemical shifts, albeit a few significant discrepancies. The chemical shift of a proton generally varies greatly with its electronic environment. An electron-withdrawing atom or group decreases shielding and thus moves the chemical shift of an attached or near-by proton towards a higher frequency (low-field). On the other hand, an electron-donating atom or group increases shielding and moves the chemical shift towards a lower frequency (high-field) [33]. For A1 and its complexes, the calculated ${ }^{1} \mathrm{H}$ NMR chemical shifts of H27 (5.68-6.02 ppm) and H28 (5.16-5.54 ppm) in the $\mathrm{NH}_{2}$ group and that of $\mathrm{H} 23$ (8.73$8.90 \mathrm{ppm}$ ) in $\mathrm{N}-\mathrm{H}$ appeared slightly shifted upfield relative to the corresponding experimental values $(7.52-7.90 \mathrm{ppm}$ for $\mathrm{H} 27, \mathrm{H} 28$ and $8.80-10.85 \mathrm{ppm}$ for $\mathrm{H} 23$ ). This is most likely due to the involvement of these hydrogen atoms in intermolecular hydrogen bonds with the neighboring molecules in the experimental sample, whereas the PCM method did not take such hydrogen bonds into account during the GIAO calculations in DMSO. H23 is the least shielded proton in all molecules studied due to the electron-withdrawing effect of N22 and to some extent N21. Consequently, its theoretical chemical shift appears downfield in the range 8.73-8.90 ppm. The calculated ${ }^{1} \mathrm{H}$ NMR signals of the highly shielded protons $(\mathrm{H} 3, \mathrm{H} 4$ and $\mathrm{H} 5)$ in $-\mathrm{OCH}_{3}$ appear in the high-field region of the NMR spectra in the range 3.83-4.25 ppm. Generally, chemical shifts in the range 6.5-8.5 ppm indicate the presence of benzene ring protons in a molecule [34]. The calculated chemical shifts of the phenyl protons (H12, H13, H14, and H15) are found in the range 7.18-7.68 ppm, which is in good agreement with the literature.

The calculated ${ }^{13} \mathrm{C}$ NMR spectra have shown that each investigated molecule contains ten carbon atoms in different electronic environments. Literature survey has shown that the ${ }^{13} \mathrm{C}$ chemical shifts of aromatic carbon atoms typically occur in the range 100-200 ppm [33]. The theoretical ${ }^{13} \mathrm{C}$ NMR chemical shifts of the benzene ring carbons (C6, 
C7, C8, C9, C10, and C11) in $\mathbf{A 1}$ and the complexes are found in the range 108.53-160.29 ppm which is in excellent agreement with the literature. The chemical shifts of these phenyl carbons are found to increase in the order $\mathrm{C} 7<\mathrm{C} 11$ $<\mathrm{C} 9<\mathrm{C} 10<\mathrm{C} 8<\mathrm{C} 6$ in each molecule, implying that the phenyl carbons are in different electronic environments created mainly by the electron-donating effect of the attached $-\mathrm{OCH}_{3}$ group. Indeed, the $-\mathrm{OCH}_{3}$ group is a powerful ortho, para-director [33], and its electron-donating effect is mainly felt by the ortho and para carbons.

3.7. Frontier Molecular Orbital Analysis. Frontier molecular orbitals (FMOs), which are the highest occupied molecular orbital (HOMO) and the lowest unoccupied molecular orbital (LUMO), are very important quantum chemical parameters because they play a key role in the electric, chemical, and optical properties of compounds [28, 35]. To gain a deeper insight into the nature of the electronic transitions in a molecular species, a detailed examination of its FMOs is crucial owing to their close relationship with electronic excitation properties [36]. To better scrutinize the electronic absorption spectra of A1 and its complexes B$\mathbf{E}$, an in-depth qualitative and quantitative analysis of their pertinent FMOs (those directly participating in the dominant electronic transitions) has been carried out. In order to facilitate qualitative analysis on these FMOs, their electron density isosurfaces (shown in Figure 6) were generated with the aid of the Avogadro 1.1.1 [37] graphical user interface. A deeper insight into the nature of the FMOs has been gained via a quantitative analysis based on orbital contributions from different fragments of ligand $\mathbf{A} \mathbf{1}$ and its complexes. The orbital contributions were calculated using the Hirshfeld method [38] as implemented in Multiwfn 3.3.6. The percentage orbital contributions together with the main bond types in each of these FMOs are presented in Table 5.

It can be seen from the molecular orbital diagrams in Figure 6 that the HOMO and LUMO of ligand Al are mainly distributed over the TSC moiety and the benzene ring. Inspection of Table 5 has shown that the HOMO of $\mathbf{A} \mathbf{1}$ is significantly contributed $(40.80 \%)$ by a $p$-type orbital located on the sulfur atom S25, designated $p(\mathrm{~S} 25)$. An insignificant orbital contribution of $6.13 \%$ to the LUMO of $\mathbf{A 1}$ arises from the $p(\mathrm{~S} 25)$ orbital on the sulfur atom S25. The HOMO is dominated by $\pi$-bonding molecular orbital characteristics, in addition to the nonbonding characteristic of the $p$-type orbital on S25. On the other hand, the LUMO is dominated by $\pi^{*}$-antibonding molecular orbital characteristics. Orbital contributions from the $p$-type orbital on $\mathrm{O} 2$ to both the HOMO and LUMO of ligand $\mathbf{A l}$ are minimal.

In the case of the metal chloride complexes of $\mathbf{A 1}$, the HOMO-2 of $\mathbf{B}$ is located mainly on the ligands and is found to have an orbital contribution of $23.74 \%$ from $\pi$-type orbitals based on A1 and an orbital contribution of $68.95 \%$ from $p$-type orbitals localized on the $\mathrm{Cl}$ ligands designated $p(\mathrm{Cl})$. The HOMO-3 of $\mathbf{C}$ resides mainly on the $\mathrm{Cl}$ ligands (Cl30 and $\mathrm{Cl} 31$ ) and the $\mathrm{Pt}(\mathrm{II})$ ion and is found to have a $64.13 \%$ orbital contribution from $p(\mathrm{Cl})$ and a $24.11 \%$ orbital contribution from a $d$-type orbital based on the $\mathrm{Pt}(\mathrm{II})$ ion,
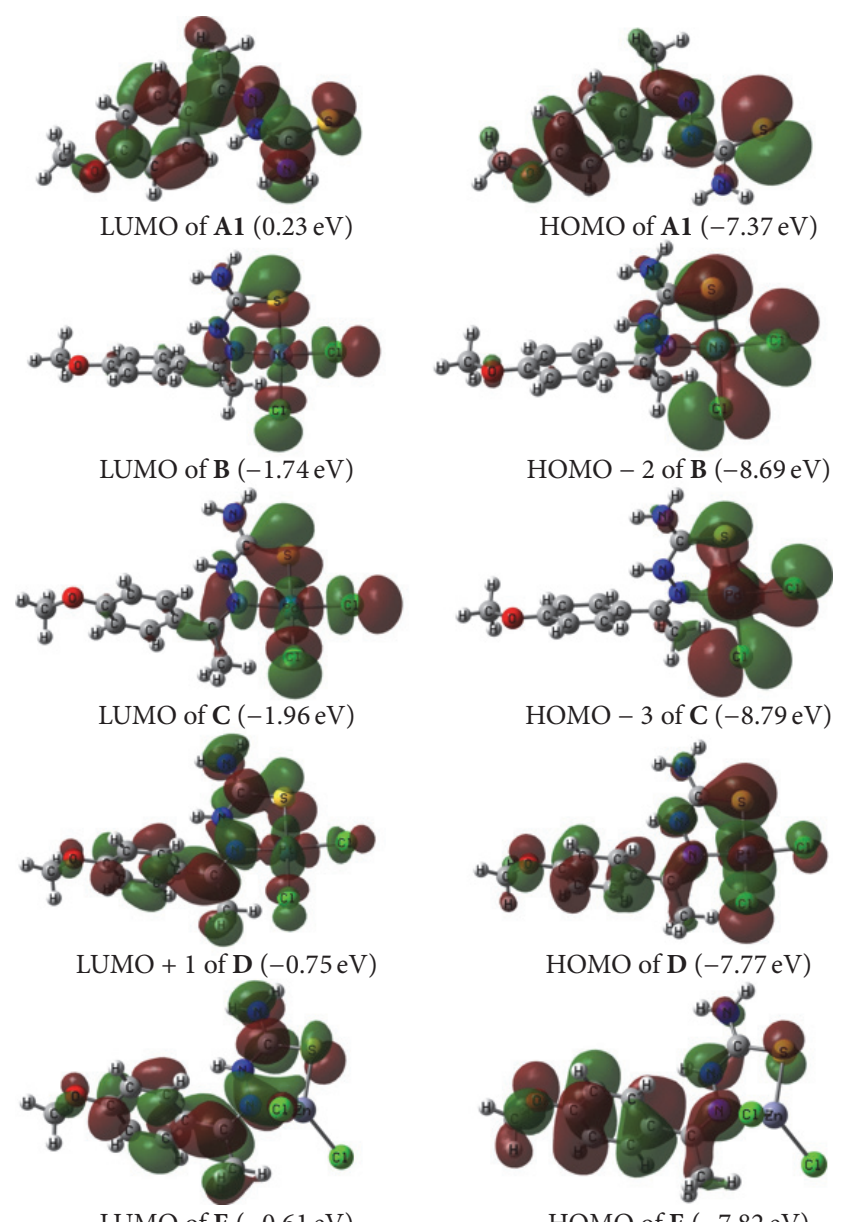

HOMO of $\mathbf{D}(-7.77 \mathrm{eV})$

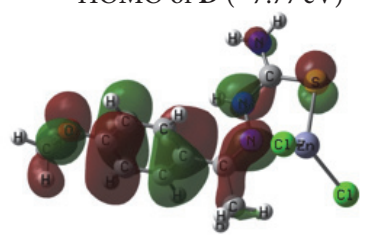

HOMO of E $(-7.82 \mathrm{eV})$

FIGURE 6: Molecular orbital diagrams for selected HOMOs and LUMOs of the molecules studied, calculated at CAM-B3LYP/6$31 \mathrm{G}(\mathrm{d}, \mathrm{p}) /(\mathrm{LANL} 2 \mathrm{DZ}$ for metal ions) level of theory in ethanol as solvent.

designated $d(\mathrm{Pt})$. The HOMO of $\mathbf{D}$ is distributed over the entire molecule and has significant orbital contributions of $30.50 \%$ and $55.80 \%$ from a $d$-type orbital based on the Pd(II) ion, designated $d(\mathrm{Pd})$, and from $\pi$-type orbitals located on A1, respectively. The HOMO of $\mathbf{E}$ is almost entirely composed of $\pi$-type orbitals on A1 (comprising $99.19 \% \pi(\mathbf{A 1})$ ).

Apparently, the electron densities of the LUMOs of $\mathbf{B}$ and $\mathrm{C}$ are distributed over the entire molecular structures and are found to benefit from significant metallic orbital contributions of $59.54 \% d(\mathrm{Ni})$ and $49.24 \% d(\mathrm{Pt})$, respectively. They also have orbital contributions from $\pi^{*}$-type orbitals based on $\mathbf{A 1}\left(22.41 \% \pi^{*}(\mathbf{A} \mathbf{1})\right.$ in $\mathbf{B}$ and $27.21 \% \pi^{*}(\mathbf{A 1})$ in $\left.\mathbf{C}\right)$, as well as orbital contributions from $p$-type orbitals on the Cl ligands $(18.05 \% p(\mathrm{Cl})$ in $\mathbf{B}$ and $23.56 \% p(\mathrm{Cl})$ in $\mathbf{C})$. In each of these LUMOs, the $d$-type orbital on the central metal ion has been found to interact in an antibonding mode with the $\pi^{*}$ orbital on $\mathrm{A} \mathbf{1}$ and the $p$-type orbitals on the $\mathrm{Cl}$ ligands. The LUMO +1 of $\mathbf{D}$ is mainly composed of $\pi^{*}$-type orbitals localized on A1 (80.78\%). The LUMO of $\mathbf{E}$ is almost entirely dominated by $\pi^{*}$-type orbitals located on $\mathbf{A 1}$, which have contributed $96.81 \%$ of this LUMO. 
TABLE 5: Molecular orbital compositions in the ground states for A1 and the complexes B-E, calculated by the TD-DFT/CAM-B3LYP method in DMSO.

\begin{tabular}{|c|c|c|c|c|c|c|}
\hline \multirow{2}{*}{$\begin{array}{l}\text { Molecule } \\
\text { Ligand }\end{array}$} & \multicolumn{2}{|c|}{ Molecular orbital } & \multicolumn{3}{|c|}{ Molecular orbital composition (\%) } & \multirow{2}{*}{ Main bond type } \\
\hline & Index & Type $^{\mathrm{a}}$ & $\mathbf{A l}^{\# \mathrm{~b}}$ & $\mathrm{O} 2$ atom & S25 atom & \\
\hline \multirow{2}{*}{ A1 } & 60 & $\mathrm{~L}$ & 91.70 & 2.17 & 6.13 & $\pi^{*}\left(\mathbf{A l}^{\#}\right)$ \\
\hline & 59 & $\mathrm{H}$ & 52.77 & 6.43 & 40.80 & $\pi\left(\mathbf{A l}^{\#}\right)+p(\mathrm{~S} 25)$ \\
\hline Complexes & Index & Type & $\mathrm{M}(\mathrm{II})^{\mathrm{c}}$ & Ligand A1 & $\mathrm{Cl}$ ligands & \\
\hline \multirow{2}{*}{ B } & 86 & $\mathrm{~L}$ & 59.54 & 22.41 & 18.05 & $d(\mathrm{Ni})$ \\
\hline & 83 & $\mathrm{H}-2$ & 7.31 & 23.74 & 68.95 & $p(\mathrm{Cl})$ \\
\hline \multirow{2}{*}{ C } & 86 & $\mathrm{~L}$ & 49.24 & 27.21 & 23.56 & $d(\mathrm{Pt})$ \\
\hline & 82 & $\mathrm{H}-3$ & 24.11 & 11.75 & 64.13 & $p(\mathrm{Cl})$ \\
\hline \multirow{2}{*}{ D } & 87 & $\mathrm{~L}+1$ & 13.35 & 80.78 & 5.86 & $\pi^{*}(\mathrm{~A} \mathbf{1})$ \\
\hline & 85 & $\mathrm{H}$ & 30.50 & 55.80 & 13.70 & $d(\mathrm{Pd})+\pi(\mathbf{A} \mathbf{1})$ \\
\hline \multirow{2}{*}{ E } & 83 & $\mathrm{~L}$ & 2.70 & 96.81 & 0.49 & $\pi^{*}(\mathbf{A} 1)$ \\
\hline & 82 & $\mathrm{H}$ & 0.33 & 99.19 & 0.48 & $\pi(\mathbf{A 1})$ \\
\hline
\end{tabular}

${ }^{\mathrm{a}} \mathrm{L}$ stands for LUMO and $\mathrm{H}$ stands for HOMO.

${ }^{\mathrm{b}} \mathbf{A l}^{\#}$ represents ligand $\mathbf{A} \mathbf{l}$ without molecular orbital contributions from atoms $\mathrm{O} 2$ and S25.

${ }^{\mathrm{c}} \mathrm{M}$ (II) represents the central metal ion which is $\mathrm{Ni}$ (II) for $\mathbf{B}, \mathrm{Pt}(\mathrm{II})$ for $\mathbf{C}, \mathrm{Pd}(\mathrm{II})$ for $\mathbf{D}$, and $\mathrm{Zn}$ (II) for $\mathbf{E}$.

3.8. Electronic Absorption Spectra. The vertical absorption spectra of the compounds currently investigated were calculated based on their optimized ground state geometries, using the TD-DFT method at the CAM-B3LYP/6$31 \mathrm{G}(\mathrm{d}, \mathrm{p}) /(\mathrm{LANL} 2 \mathrm{DZ}$ for metal ions) level of theory. These calculations were carried out in two solvents with different dielectric constants $(\varepsilon)$, ethanol with $\varepsilon=24.85$ and DMSO with $\varepsilon=46.83$, for comparison. TD-DFT is a powerful method that is commonly used nowadays in modeling electronic transitions and excited state geometries of organic and inorganic molecules [39]. Its success arises from the remarkable accuracy/computational-time ratio. However, TD-DFT significantly underestimates excitation energies to charge transfer (CT) or Rydberg states when conventional exchangecorrelation functionals are used [40]. This is due to the poor asymptotic behavior of conventional exchange-correlation functionals in approximations to ground state [41]. In order to partially correct this shortcoming, we adopted the rangeseparated exchange-correlation coulomb-attenuated model (CAM-B3LYP) functional to overcome some of the deficiencies of B3LYP in dealing with CT excitations [42-44].

The calculated vertical excitation energies, wavelengths, oscillator strengths $(f)$, assignments, configurational interaction $(\mathrm{CI})$ coefficients, and percentage contributions $(P)$ of transitions for $\mathbf{A} \mathbf{1}$ and complexes $\mathbf{B}-\mathbf{E}$ are listed in Table 6, along with the experimental transition wavelengths for A1 and complexes $\mathbf{B}-\mathbf{D}$ for comparison. To obtain the nature and energies of the singlet-singlet vertical electronic transitions, the first six low-lying excited states have been calculated. Generally, the dominant band in an absorption spectrum corresponds to the transition with the largest oscillator strength [44] and its wavelength is comparable to the experimental $\lambda_{\max }$. In the current study, only the absorption energies with the greatest oscillator strengths have been considered. The commonest vertical electronic transitions in organic molecules are of $\pi \rightarrow \pi^{*}$ or $n \rightarrow \pi^{*}$ type, whereas, in metal complexes, the involvement of the metal $d$-orbitals leads to metal-to-ligand charge transfer (MLCT) transitions, which involve electronic excitations from mainly metal-based $d$ orbitals to low-lying empty ligand orbitals, $d$ - $d$ transitions, which occur between partially filled metallic $d$-orbitals, and ligand-to-metal charge transfer (LMCT) transitions, which occur from filled ligand based orbitals to partially occupied metal $d$-orbitals $[45,46]$. In addition, intraligand charge transfer (ILCT) transitions, which involve electronic excitations between orbitals based on the same ligand as well as ligand-to-ligand charge transfer (LLCT) transitions, in which an electron is moved from one ligand to another, may also occur in metal complexes.

To explore the performance of the computational procedure employed in the computation of the electronic absorption spectra, we compared calculated and experimental wavelengths of maximum absorption $\left(\lambda_{\max }\right)$. It can be seen from Table 6 that the agreement between theoretical and experimental values of $\lambda_{\max }$ is excellent, with a maximum discrepancy of only $25 \mathrm{~nm}$. Furthermore, we determined the correlation between these two sets of data as shown in (4), and an excellent linear relationship was found:

$$
\lambda_{\text {max.cal }}=0.756 \lambda_{\text {max.exp }}+71.61 \quad\left(R^{2}=0.931\right) .
$$

In this equation, $\lambda_{\text {max.cal }}$ and $\lambda_{\text {max.exp }}$ are calculated and experimental wavelengths of maximum absorption, respectively.

By inspection of the UV-Vis data in Table 6 for the molecules currently investigated, their dominant electronic transitions in ethanol and DMSO as solvents are found to be very similar in terms of band positions, although their intensities differ slightly. The electronic excitation bands for these molecules are therefore not affected as such by high solvent polarities. On the basis of FMO analysis, the peak at $257 \mathrm{~nm}$ in the absorption spectrum of $\mathbf{A 1}$ is assigned to both $\pi \rightarrow \pi^{*}$ and $n \rightarrow \pi^{*}$ electronic transitions. The most intense absorption bands in the spectra of $\mathbf{B}$ and $\mathbf{C}$ are observed at 
TABLE 6: Excitation energies and wavelengths, oscillator strengths, configuration interaction (CI) coefficients, and dominant electronic transitions for A1 and complexes B-E in different solvents, calculated using the TD-DFT/CAM-B3LYP method.

\begin{tabular}{|c|c|c|c|c|c|c|c|c|c|}
\hline Solvent & $\begin{array}{l}\text { Ligand or } \\
\text { complex }\end{array}$ & $\begin{array}{c}\text { Singlet } \\
\text { excited state }\end{array}$ & $\begin{array}{l}\text { Dominant } \\
\text { electronic } \\
\text { transition }\end{array}$ & $\begin{array}{c}\text { CI } \\
\text { coefficient } \\
(P= \\
\left.2|\mathrm{CI}|^{2} \times 100\right)\end{array}$ & $\begin{array}{c}\text { Excitation } \\
\text { energy } \\
(\mathrm{eV})\end{array}$ & $\begin{array}{l}\text { Oscillator } \\
\text { strength } \\
\quad(f)\end{array}$ & $\begin{array}{l}\mathrm{Cal}^{\mathrm{a}} \lambda_{\max } \\
\quad(\mathrm{nm})\end{array}$ & $\begin{array}{l}\text { Exp. }^{\mathrm{b}} \lambda_{\max } \\
\quad(\mathrm{nm})\end{array}$ & Assignment \\
\hline \multirow{5}{*}{ Ethanol } & A1 & $\mathrm{S}_{2}$ & $\mathrm{H} \rightarrow \mathrm{L}$ & $\begin{array}{c}0.5550 \\
(61.6 \%)\end{array}$ & 4.83 & 0.7799 & 257 & 260 & $n \rightarrow \pi^{*} / \pi \rightarrow \pi^{*}$ \\
\hline & B & $\mathrm{S}_{5}$ & $\mathrm{H}-2 \rightarrow \mathrm{L}$ & $\begin{array}{c}0.5954 \\
(70.9 \%)\end{array}$ & 3.49 & 0.0325 & 355 & 330 & LMCT \\
\hline & $\mathrm{C}$ & $\mathrm{S}_{5}$ & $\mathrm{H}-3 \rightarrow \mathrm{L}$ & $\begin{array}{c}0.5381 \\
(57.9 \%)\end{array}$ & 3.61 & 0.0325 & 344 & 340 & LMCT \\
\hline & D & $\mathrm{S}_{5}$ & $\mathrm{H} \rightarrow \mathrm{L}+1$ & $0.6111(74.7 \%)$ & 4.25 & 0.4319 & 291 & 300 & MLCT/ILCT \\
\hline & $\mathbf{E}$ & $\mathrm{S}_{1}$ & $\mathrm{H} \rightarrow \mathrm{L}$ & $\begin{array}{c}0.6668 \\
(88.9 \%)\end{array}$ & 4.55 & 0.6550 & 273 & - & ILCT \\
\hline \multirow{5}{*}{ DMSO } & A1 & $\mathrm{S}_{2}$ & $\mathrm{H} \rightarrow \mathrm{L}$ & $\begin{array}{c}0.5799 \\
(67.3 \%)\end{array}$ & 4.82 & 0.7968 & 257 & 260 & $n \rightarrow \pi^{*} / \pi \rightarrow \pi^{*}$ \\
\hline & B & $\mathrm{S}_{5}$ & $\mathrm{H}-2 \rightarrow \mathrm{L}$ & $\begin{array}{c}0.5881 \\
(69.2 \%)\end{array}$ & 3.52 & 0.0349 & 352 & 330 & LMCT \\
\hline & $\mathrm{C}$ & $\mathrm{S}_{5}$ & $\mathrm{H}-3 \rightarrow \mathrm{L}$ & $\begin{array}{c}0.4821 \\
(46.5 \%)\end{array}$ & 3.65 & 0.0363 & 340 & 340 & LMCT \\
\hline & D & $\mathrm{S}_{5}$ & $\mathrm{H} \rightarrow \mathrm{L}+1$ & $\begin{array}{c}0.6137 \\
(75.3 \%)\end{array}$ & 4.26 & 0.4864 & 291 & 300 & MLCT/ILCT \\
\hline & $\mathbf{E}$ & $\mathrm{S}_{1}$ & $\mathrm{H} \rightarrow \mathrm{L}$ & $\begin{array}{c}0.6669 \\
(88.9 \%)\end{array}$ & 4.53 & 0.6650 & 274 & - & ILCT \\
\hline
\end{tabular}

${ }^{\mathrm{a}}$ Calculated $\lambda_{\max }$ in this work.

${ }^{\mathrm{b}}$ Experimental $\lambda_{\max }$ obtained from [9].

352 and $340 \mathrm{~nm}$ and can be attributed to LMCT transitions on the basis of FMO analysis. These bands are produced by electronic transitions from $p$-type orbitals located on the $\mathrm{Cl}$ ligands $[p(\mathrm{Cl})]$ to $d$-type orbitals on the central metal ions $[d(\mathrm{Ni})$ and $d(\mathrm{Pt})]$. The band at $291 \mathrm{~nm}$ in the spectrum of $\mathrm{D}$ arises from the electronic excitation HOMO $\rightarrow$ LUMO + 1. Here, the HOMO is comprised mainly of $30.50 \% d(\mathrm{Pd})$ and $55.80 \% \pi(\mathbf{A 1})$, and the LUMO +1 is almost entirely composed of $80.78 \% \pi^{*}$ (A1) (see Table 5). Therefore, this signal arises from the electronic transition $[d(\mathrm{Pd})+\pi(\mathbf{A 1})] \rightarrow$ $\left[\pi^{*}(\mathbf{A l})\right]$ with a mixed MLCT and ILCT character. An intense band at $274 \mathrm{~nm}$ is present in the absorption spectrum of $\mathbf{E}$ with ILCT character, solely attributable to $\pi \rightarrow \pi^{*}$ electronic transition between A1-based orbitals.

The theoretical absorption spectra for A1 and its complexes in DMSO as solvent have been compared graphically as shown in Figure 7. It is evidenced in this figure that the values of $\lambda_{\max }$ for the transition metal chloride complexes of $\mathbf{A l}$ are red shifted compared to that of the free ligand. This bathochromic shift of $\lambda_{\text {max }}$ upon A1- $\mathrm{MCl}_{2}$ complexation can be attributed to the involvement of low-lying metalbased orbitals in electronic transitions. This upper shift of $\lambda_{\max }$ upon transition from $\mathbf{A 1}$ to its complexes corresponds to a reduction in maximum excitation energy in the order A1 $>\mathbf{E}>\mathbf{D}>\mathbf{C}>\mathbf{B}$, indicating that intramolecular charge transfer (ICT) is more significant in the complexes than in the free ligand. This accounts for the greater lipophilicity of these complexes (which controls permeation into the cell and hence their biological activity), since lipophilicity depends on intramolecular charge delocalization [47].

\section{Conclusion}

A DFT study on the structural and spectral properties of MAPTSC and its $\mathrm{Ni}(\mathrm{II}), \mathrm{Pd}(\mathrm{II}), \mathrm{Pt}(\mathrm{II})$, and $\mathrm{Zn}(\mathrm{II})$ chloride complexes and on thione-thiol tautomerism of MAPTSC has been carried out with the aim of deepening the understanding of their structure-activity relationships, necessary for rational drug design. The DFT/B3LYP and DFT/CAM-B3LYP methods in gas and solvent phases have been employed in this study in conjunction with different basis sets. The barrier heights for thione-to-thiol and thiol-to-thione tautomerization of MAPTSC, determined via hydrogen atom migration studies in ethanol as solvent, are $\approx 46.41$ and $32.51 \mathrm{kcal} / \mathrm{mol}$, respectively. These high barrier heights indicate that thionethiol interconversions of MAPTSC in ethanolic solution are nearly hindered at room temperature. Nevertheless, MAPTSC would undergo rapid thione-thiol transformations in ethanol at higher temperatures. Tautomerism analysis has shown that the thione tautomer of MAPTSC is more stable than the thiol counterpart in ethanol. Therefore, MAPTSC can exist as a mixture of the thione (major) and thiol (minor) tautomers in ethanolic solution at room and higher temperatures. Consequently, metal complexes of MAPTSC synthesized in ethanolic solution at temperatures well above 


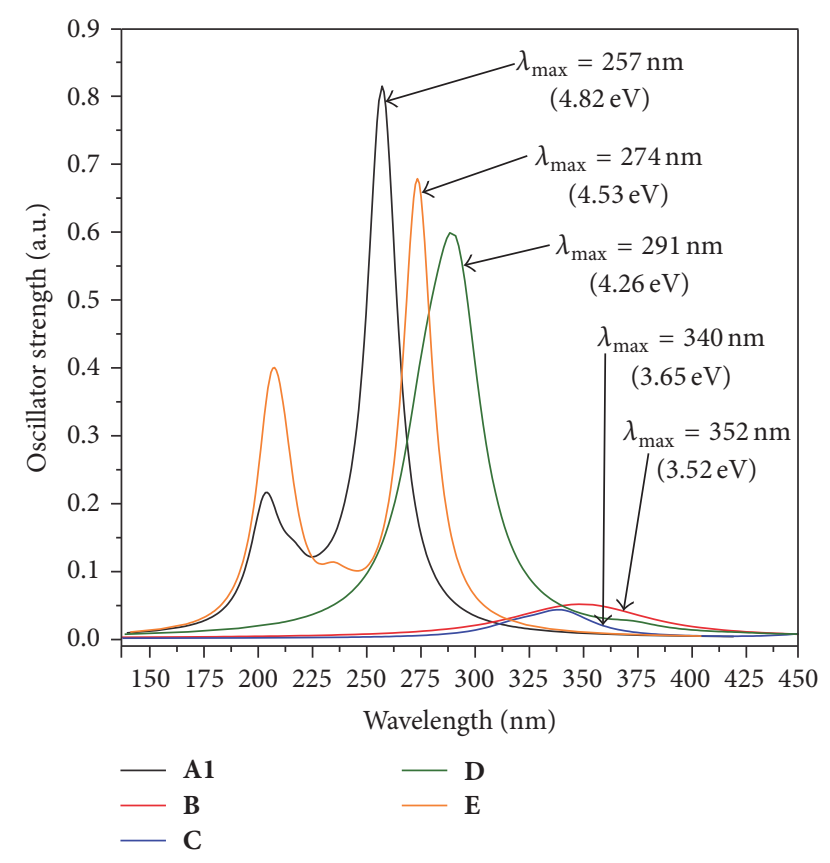

FIgURE 7: Calculated absorption spectra for $\mathbf{A} 1$ and complexes $\mathbf{B}-\mathbf{E}$ in DMSO.

$25^{\circ} \mathrm{C}$ will likely be composed of a mixture of thione- and thiolbased complexes.

Conformational analysis has revealed five possible conformers of the thione tautomer of which two are stable enough to be isolated at $25^{\circ} \mathrm{C}$. The thione tautomer of MAPTSC exhibits a higher affinity for the $\mathrm{d}^{8}$ metal ions $\mathrm{Ni}(\mathrm{II}), \mathrm{Pd}(\mathrm{II})$, and $\mathrm{Pt}(\mathrm{II})$ as shown by the computed values of MAPTSC-metal(II) binding energies, enthalpies, and Gibbs free energies and can therefore efficiently chelate them in chemical and biological systems. Natural population analysis has revealed ligand-metal charge transfer in the MAPTSC complexes studied. Intramolecular charge transfer (ICT) has been found to be more significant in the complexes than in uncomplexed MAPTSC, accounting for the greater lipophilicity (which controls permeation into the cell and hence their biological activity) of these complexes. A good agreement has been found between calculated and experimentally observed spectral properties (IR, UV-Vis, and NMR).

\section{Additional Points}

Supporting Information. The optimized geometries of the transition states TS1, TS2, TS3, and TS4 are shown in Figure S1. Selected geometric parameters of the thione-thiol tautomers of MAPTSC (A1 and A2) along with those of their transition metal chloride complexes, calculated at B3LYP/6$31++G(d, p) /(S D D$ for metal ions) level of theory in gas phase, are summarized in Table S3. MPA and NPA atomic charges on selected atoms of $\mathbf{A} \mathbf{1}$ and its metal chloride complexes, calculated at B3LYP/6-31++G(d,p)/(SDD for metal ions) level of theory in ethanol as solvent, are listed in Table S4.

\section{Competing Interests}

The authors declare that there is no conflict of interests regarding the publication of this paper.

\section{Acknowledgments}

The authors are sincerely thankful to the IIT Kanpur, India, for the resources put at their disposal through a CV Raman International Fellowship Award (Grant no. 101F102), offered to Julius Numbonui Ghogomu by the Ministry of External Affairs of India and the Federation of Indian Chambers of Commerce and Industry (FICCI).

\section{References}

[1] R. Santhakumari, K. Ramamurthi, G. Vasuki, B. M. Yamin, and G. Bhagavannarayana, "Synthesis and spectral characterization of acetophenone thiosemicarbazone: a nonlinear optical material," Spectrochimica Acta-Part A: Molecular and Biomolecular Spectroscopy, vol. 76, no. 3-4, pp. 369-375, 2010.

[2] A. A. Al-Amiery, Y. K. Al-Majedy, H. Abdulreazak, and H. Abood, "Synthesis, characterization, theoretical crystal structure, and antibacterial activities of some transition metal complexes of the thiosemicarbazone (Z)-2-(pyrrolidin-2-ylidene)hydrazinecarbothioamide," Bioinorganic Chemistry and Applications, vol. 2011, Article ID 483101, 6 pages, 2011.

[3] M. Adams, C. de Kock, P. J. Smith, K. Chibale, and G. S. Smith, "Synthesis, characterization and antiplasmodial evaluation of cyclopalladated thiosemicarbazone complexes," Journal of Organometallic Chemistry, vol. 736, pp. 19-26, 2013.

[4] J. L. Bautista, M. Flores-Alamo, J. Tiburcio, R. Vieto, and H. Torrens, "Synthesis and structural characterization of fluorinated thiosemicarbazones," Molecules, vol. 18, no. 10, pp. 13111-13123, 2013.

[5] R. Harness, C. Robertson, and F. Beckford, "Thiosemicarbazone complexes of group 12 elements. An investigation of the thiosemicarbazone from p-dimethylaminobenzaldehyde," Journal of Undergraduate Chemistry Research, vol. 7, no. 3, pp. 92-97, 2008.

[6] S. M. Kumar, K. Dhahagani, J. Rajesh et al., "Synthesis, characterization, structural analysis and DNA binding studies of nickel(II)-triphenylphosphine complex of ONS donor ligandmultisubstituted thiosemicarbazone as highly selective sensor for fluoride ion," Polyhedron, vol. 59, pp. 58-68, 2013.

[7] G. Pelosi, “Thiosemicarbazone metal complexes: from structure to activity," The Open Crystallography Journal, vol. 3, no. 2, pp. $16-28,2010$.

[8] H. R. Fatondji, S. Kpoviessi, F. Gbaguidi et al., "Structureactivity relationship study of thiosemicarbazones on an African trypanosome: Trypanosoma brucei brucei," Medicinal Chemistry Research, vol. 22, no. 5, pp. 2151-2162, 2013.

[9] R. Kothari and B. Sharma, "Synthesis, characterization, antibacterial, antifungal, antioxidant and dna interaction studies of thiosemicarbazone transition metal complexes," World Journal of Pharmacy and Pharmaceutical Sciences, vol. 3, no. 7, pp. 10671080, 2014.

[10] S. Stoyanov, I. Petkov, L. Antonov, T. Stoyanova, P. Karagiannidis, and P. Aslanidis, "Thione-thiol tautomerism and stability of 2- and 4-mercaptopyridines and 2-mercaptopyrimidines," 
Canadian Journal of Chemistry, vol. 68, no. 9, pp. 1482-1489, 1990.

[11] Y. Xue, Y. Liu, L. An et al., "Electronic structures and spectra of quinoline chalcones: DFT and TDDFT-PCM investigation," Computational and Theoretical Chemistry, vol. 965, no. 1, pp. 146-153, 2011.

[12] T. C. Zeyrek, "Theoretical study of the N-(2,5-Methylphenyl)salicylaldimine schiff base ligand: atomic charges, molecular electrostatic potential, nonlinear optical (NLO) effects and thermodynamic properties," Journal of the Korean Chemical Society, vol. 57, no. 4, pp. 461-471, 2013.

[13] F. Billes, A. Holmgren, and H. Mikosch, "A combined DFT and vibrational spectroscopy study of the nickel and zinc O,Odiethyldithiophosphate complexes," Vibrational Spectroscopy, vol. 53, no. 2, pp. 296-306, 2010.

[14] M. J. Frisch, G. W. Trucks, H. B. Schlegel et al., Gaussian 09, Revision A.02, Gaussian, Inc., Wallingford, Conn, USA, 2009.

[15] R. D. Dennington II, T. A. Keith, and J. M. Millam, Gauss View 5.0.8, Gaussian Inc., Wallingford, Conn, USA, 2009.

[16] T. Lu and F. Chen, "Multiwfn: a multifunctional wavefunction analyzer," Journal of Computational Chemistry, vol. 33, no. 5, pp. 580-592, 2012.

[17] A. D. Becke, "Density-functional thermochemistry. III. The role of exact exchange," The Journal of Chemical Physics, vol. 98, no. 7, pp. 5648-5652, 1993.

[18] W.-Y. Wang, X.-F. Du, N.-N. Ma, S.-L. Sun, and Y.-Q. Qiu, "Theoretical investigation on switchable second-order nonlinear optical (NLO) properties of novel cyclopentadienylcobalt linear [4]phenylene complexes," Journal of Molecular Modeling, vol. 19, no. 4, pp. 1779-1787, 2013.

[19] R. N. Singh and P. Rawat, "Spectral analysis, structural elucidation, and evaluation of both nonlinear optical properties and chemical reactivity of a newly synthesized ethyl-3,5dimethyl-4-[(toluenesulfonyl)-hydrazonomethyl]- $1 \mathrm{H}$-pyrrole2-carboxylate through experimental studies and quantum chemical calculations," Journal of Molecular Structure, vol. 1054-1055, pp. 65-75, 2013.

[20] J. G. Małecki, A. Maroń, M. Serda, and J. Polański, "Ruthenium(II) carbonyl complexes with thiosemicarbazone ligands," Polyhedron, vol. 56, pp. 44-54, 2013.

[21] K. C. Gross, P. G. Seybold, and C. M. Hadad, "Comparison of different atomic charge schemes for predicting $\mathrm{pKa}$ variations in substituted anilines and phenols," International Journal of Quantum Chemistry, vol. 90, no. 1, pp. 445-458, 2002.

[22] M. Karnan, V. Balachandran, M. Murugan, M. K. Murali, and A. Nataraj, "Vibrational (FT-IR and FT-Raman) spectra, NBO, HOMO-LUMO, molecular electrostatic potential surface and computational analysis of 4-(trifluoromethyl)benzylbromide," Spectrochimica Acta Part A: Molecular and Biomolecular Spectroscopy, vol. 116, pp. 84-95, 2013.

[23] Y. S. Mary, P. J. Jojo, C. Y. Panicker, C. Van Alsenoy, S. Ataei, and I. Yildiz, "Theoretical investigations on the molecular structure, vibrational spectra, HOMO-LUMO and NBO analysis of 5-chloro-2-((4-chlorophenoxy)methyl)benzimidazole," Spectrochimica Acta-Part A, vol. 122, pp. 499-511, 2014.

[24] F. Weinhold and C. R. Landis, "Natural bond orbitals and extensions of localized bonding concepts," Chemistry Education: Research and Practice in Europe, vol. 2, no. 2, pp. 91-104, 2001.

[25] R. S. Mulliken, "Electronic population analysis on LCAO-MO molecular wave functions. I," The Journal of Chemical Physics, vol. 23, no. 10, pp. 1833-1840, 1955.
[26] Z. Demircioğlu, Ç. A. Kaştaş, and O. Büyükgüngör, "The spectroscopic (FT-IR, UV-vis), Fukui function, NLO, NBO, NPA and tautomerism effect analysis of (E)-2-[(2-hydroxy6-methoxybenzylidene)amino]benzonitrile," Spectrochimica Acta-Part A, vol. 139, pp. 539-548, 2015.

[27] T. Lu and S. Manzetti, "Wavefunction and reactivity study of benzo[a]pyrene diol epoxide and its enantiomeric forms," Structural Chemistry, vol. 25, no. 5, pp. 1521-1533, 2014.

[28] A. Kumar, V. Deval, P. Tandon, A. Gupta, and E. D. D'silva, "Experimental and theoretical (FT-IR, FT-Raman, UV-Vis, NMR) spectroscopic analysis and first-order hyperpolarizability studies of non-linear optical material: (2E)-3[4-(methylsulfanyl) phenyl]-1-(4-nitrophenyl) prop-2-en-1-one using density functional theory," Spectrochimica Acta Part A, vol. 130, pp. 41-53, 2014.

[29] M. Karabacak, A. Çoruh, and M. Kurt, "FT-IR, FT-Raman, NMR spectra, and molecular structure investigation of 2,3dibromo-N-methylmaleimide: a combined experimental and theoretical study," Journal of Molecular Structure, vol. 892, no. 1-3, pp. 125-131, 2008.

[30] C. J. Cramer, Essentials of Computational Chemistry: Theories and Models, John Wiley \& Sons, West Sussex, UK, 4th edition, 2004.

[31] A. T. E. Ardjani and S. M. Mekelleche, "Theoretical study of the structure, spectroscopic properties and anti-cancer activity of tetrahydrochromeno[4,3-b] quinolines," Journal of Theoretical and Computational Chemistry, vol. 14, no. 7, Article ID 1550052, 17 pages, 2015.

[32] S. Ramalingam, M. Karabacak, S. Periandy, N. Puviarasan, and D. Tanuja, "Spectroscopic (infrared, Raman, UV and NMR) analysis, gaussian hybrid computational investigation (MEP maps/HOMO and LUMO) on cyclohexanone oxime," Spectrochimica Acta Part A: Molecular and Biomolecular Spectroscopy, vol. 96, pp. 207-220, 2012.

[33] K. P. C. Vollhardt and N. E. Schore, Organic Chemistry: Structure and Function, W. H. Freeman and Company, New York, NY, USA, 5th edition, 2007.

[34] F. A. Carey, Organic Chemistry, James M. Smith, New York, NY, USA, 4th edition, 2000.

[35] R. Srivastava and L. R. Joshi, "The effect of substituted 1,2,4triazole moiety on the emission, phosphorescent properties of the blue emitting heteroleptic iridium(iii) complexes and the OLED performance: A Theoretical Study," Physical Chemistry Chemical Physics, vol. 16, no. 32, pp. 17284-17294, 2014.

[36] Y. Xue, L. An, Y. Zheng et al., "Structure and electronic spectral property of coumarin-chalcone hybrids: a comparative study using conventional and long-range corrected hybrid functionals," Computational and Theoretical Chemistry, vol. 981, pp. 9099, 2012.

[37] M. D. Hanwell, D. E. Curtis, D. C. Lonie, T. Vandermeerschd, E. Zurek, and G. R. Hutchison, "Avogadro: an advanced semantic chemical editor, visualization, and analysis platform," Journal of Cheminformatics, vol. 4, no. 8, article 17, 2012.

[38] T. Lu and F. W. Chen, "Calculation of molecular orbital composition," Acta Chimica Sinica, vol. 69, no. 20, pp. 2393-2406, 2011.

[39] R. Nithya, N. Santhanamoorthi, P. Kolandaivel, and K. Senthilkumar, "Structural and spectral properties of 4-bromo1-naphthyl chalcones: A Quantum Chemical Study," The Journal of Physical Chemistry A, vol. 115, no. 24, pp. 6594-6602, 2011.

[40] K. Kornobis, N. Kumar, B. M. Wong et al., "Electronically excited states of vitamin $\mathrm{B}_{12}$ : benchmark calculations including 
time-dependent density functional theory and correlated $a b$ initio methods," Journal of Physical Chemistry A, vol. 115, no. 7, pp. 1280-1292, 2011.

[41] X. Zárate, E. Schott, D. Mac-Leod Carey, C. Bustos, and R. Arratia-Pérez, "DFT study on the electronic structure, energetics and spectral properties of several bis(organohydrazido(2)) molybdenum complexes containing substituted phosphines and chloro atoms as ancillary ligands," Journal of Molecular Structure: THEOCHEM, vol. 957, no. 1-3, pp. 126-132, 2010.

[42] C. Adamo and D. Jacquemin, "The calculations of excited-state properties with time-dependent density functional theory," Chemical Society Reviews, vol. 42, no. 3, pp. 845-856, 2013.

[43] H. Li, Y. Li, and M. Chen, "TDDFT studies of electronic spectra and excited states of the triphenylamine-based organic sensitizers and organic sensitizer-titanium dioxide cluster complexes," RSC Advances, vol. 3, no. 30, pp. 12133-12139, 2013.

[44] J.-P. Wang, L.-K. Yan, W. Guan, S.-Z. Wen, and Z.-M. Su, "The structure-property relationship of chiral 1,1'-binaphthylbased polyoxometalates: TDDFT studies on the static first hyperpolarizabilities and the ECD spectra," Journal of Molecular Graphics and Modelling, vol. 32, pp. 1-8, 2012.

[45] T. Sivaranjani, S. Xavier, and S. Periandy, "NMR, FT-IR, FTRaman, UV spectroscopic, HOMO-LUMO and NBO analysis of cumene by quantum computational methods," Journal of Molecular Structure, vol. 1083, pp. 39-47, 2015.

[46] C. Latouche, D. Skouteris, F. Palazzetti, and V. Barone, "TDDFT Benchmark on inorganic Pt(II) and Ir(III) complexes," Journal of Chemical Theory and Computation, vol. 11, no. 7, pp. 3281-3289, 2015.

[47] V. Chopineaux-Courtois, F. Reymond, G. Bouchard, P.-A. Carrupt, B. Testa, and H. H. Girault, "Effects of charge and intramolecular structure on the lipophilicity of nitrophenols," Journal of the American Chemical Society, vol. 121, no. 8, pp. 1743-1747, 1999. 

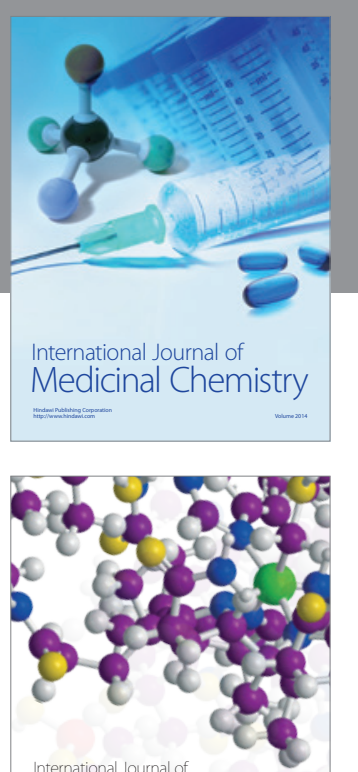

Carbohydrate Chemistry

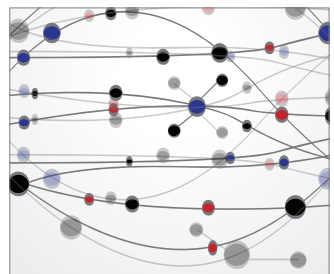

The Scientific World Journal
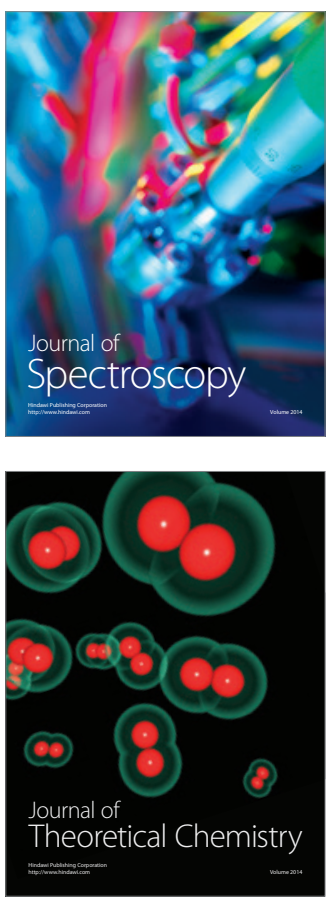
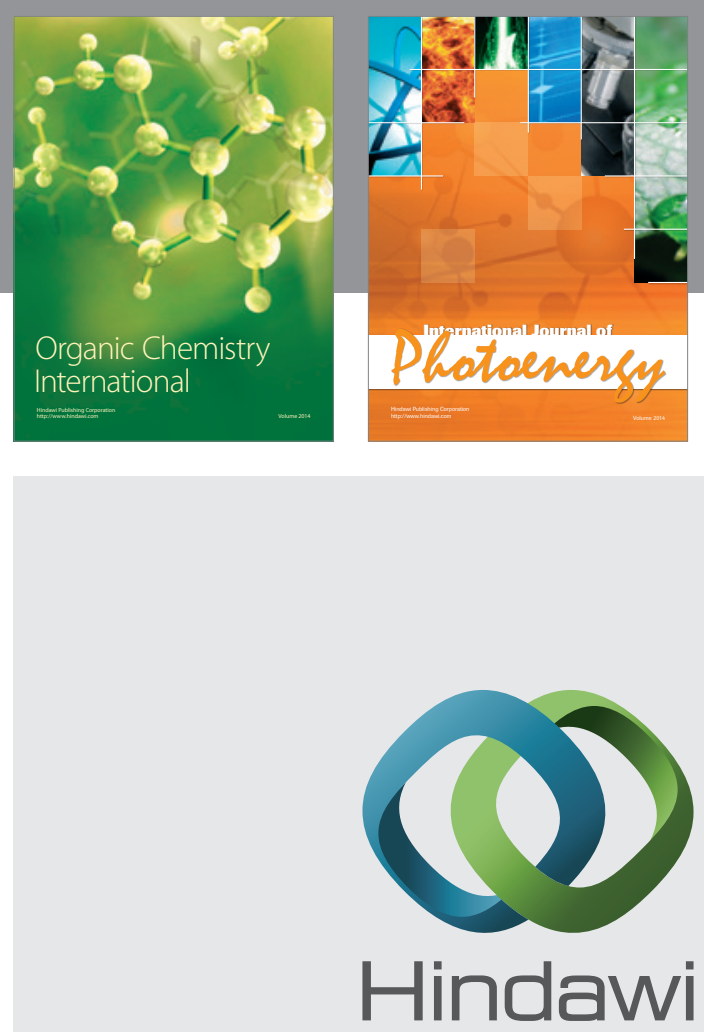

Submit your manuscripts at

http://www.hindawi.com

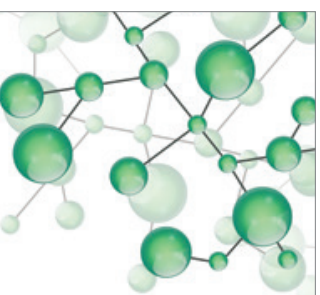

International Journal of

Inorganic Chemistry

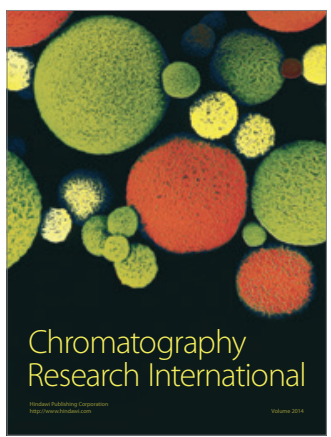

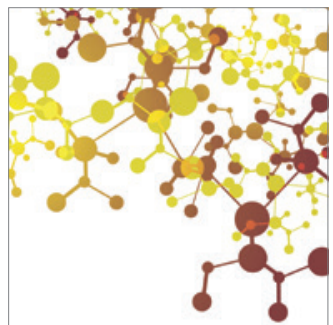

Applied Chemistry
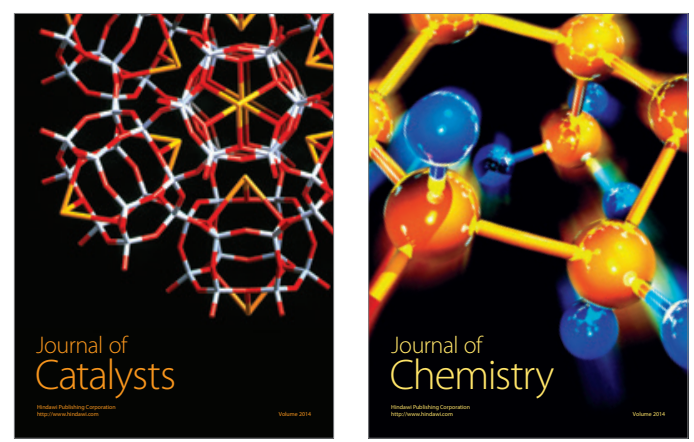
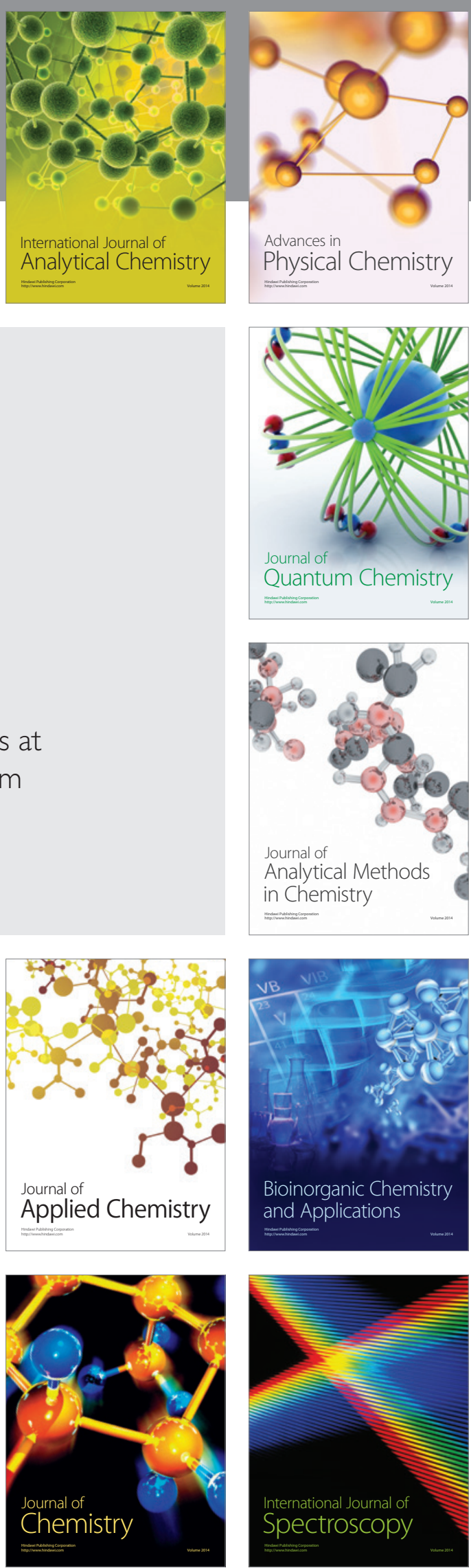